\title{
Jurassic-Cretaceous and Cretaceous-Paleogene Transitions and Mesozoic Vertebrates from Pakistan
}

\author{
Muhammad Sadiq Malkani \\ Geological Survey of Pakistan, Muzaffarabad, Pakistan \\ Email: malkanims@yahoo.com
}

How to cite this paper: Malkani, M.S. (2021) Jurassic-Cretaceous and CretaceousPaleogene Transitions and Mesozoic Vertebrates from Pakistan. Open Journal of $\mathrm{Ge}$ ology, 11, 275-318.

https://doi.org/10.4236/ojg.2021.118016

Received: July 2, 2021

Accepted: August 2, 2021

Published: August 5, 2021

Copyright $\odot 2021$ by author(s) and Scientific Research Publishing Inc. This work is licensed under the Creative Commons Attribution International License (CC BY 4.0).

http://creativecommons.org/licenses/by/4.0/

\begin{abstract}
The Jurassic-Cretaceous $(\mathrm{J} / \mathrm{K})$ and Cretaceous-Paleogene (K/Pg) boundaries/ transitions are found in Pakistan especially well exposed on the western continental margin of the Indo-Pakistan plate (part of Gondwana) like Kirthar, Sulaiman and Kohat and Potwar basins. Its lithology is variable both lateral and also vertical. The $\mathrm{J} / \mathrm{K}$ and $\mathrm{K} / \mathrm{Pg}$ transitions are represented by terrestrial and marine strata like laterite, bauxite, vary colored shale, sandstones and conglomerates and rare limestone beds. Mesozoic vertebrates found so far belong to archosaurs like poripuchian titanosaurs (sauropods), theropods, mesoeucrocodiles, pterosaurs, snake and bird are briefly overviewed here.
\end{abstract}

\section{Keywords}

J/K Transition, K/Pg Boundary, Cretaceous, Poripuchian Titanosaurs, Theropods, Mesoeucrocodiles, Pterosaurs, Snake, Bird, Pakistan

\section{Introduction}

Here the marine and terrestrial strata of Jurassic-Cretaceous $(\mathrm{J} / \mathrm{K})$ and Cretaceous-Paleogene $(\mathrm{K} / \mathrm{Pg})$ transitions in Pakistan are presented which are well exposed in north Indus (Kohat-Potwar basin), middle/central Indus (Sulaiman basin) and south Indus (Kirthar basin). The biota and these transitions are significant due to northward migration of the Indo-Pakistan subcontinental plate from southern earth to northern earth and also extinction phenomena. The $\mathrm{J} / \mathrm{K}$ boundary yielded a few bones of basal titanosaurs. The strata just below the K/Pg boundary yielded about 3000 bones/pieces of bones of the latest Maastrichtian archosaurs. Further, the nomenclature requirements like systematic paleontolo- 
gy, etymology, designation of holotype, declaration of new genus/new species/new group, type locality, horizon and age, diagnosis and description with comparisons of previously reported along with a few new Mesozoic archosaurs found from $\mathrm{Pa}$ kistan are being presented.

Institutional Abbreviations: GSP, Geological Survey of Pakistan, Quetta, Pakis$\tan$.

\section{Materials and Methods}

The materials belong to compiled data from previous work especially mentioned in references and also new field data collected by the present author during numerous field seasons regarding the lithology, stratigraphy, paleontology of $\mathrm{Pa}$ kistan. The methods applied here are many disciplines of purely geological and paleontological methods and description.

\section{Results and Discussion}

Here the results and discussion are represented as the Jurassic-Cretaceous transition, Cretaceous-Paleogene transition, Titanosauriformes, titanosaurian sauropods, theropods, mesoeucrocodiles, pterosaur, snake and bird from the latest Maastrichtian (latest Cretaceous) Vitakri Formation, and footprints and trackways from latest Jurassic and latest Cretaceous strata of Pakistan.

\subsection{Jurassic/Cretaceous Transition in Pakistan, Its Distribution and Lithological Variations}

The Jurassic-Cretaceous transition is well exposed [1] [2] [3] in Indus basin (Figure 1) of Pakistan which is a fragment and geoheritage of Gondwanalands (southern earth hemisphere), however it is also exposed in Chapursan valley of Karakoram basin which is a part of Asian (Laurasian, northern earth hemisphere). The Kohistan-Ladakh magmatic arc and Balochistan basin has no well exposure of Jurassic-Cretaceous transition or boundary. In Indus basin of Pakistan, the Jurassic-Cretaceous boundary is well exposed in the north/upper, middle/central and south/lower Indus basin. The Jurassic is well represented by ammonite and titanosauriforms/basal titanosaurs while Cretaceous is well known by belemnite and diverse archosaurs. The Jurassic strata of north Indus basin are represented by terrestrial fluvial Datta sandstones, following by marine Shinawari shale and limestone and Samana Suk limestone. Here the J/K transition (Figure 2) is represented by grey limestone and shale of uppermost part of Late Jurassic Samanasuk formation and green glauconitic shale with negligible sandstone of lower part of Early Cretaceous Chichali Formation. This lithological transition is well exposed in the western part of north Indus like in Mianwali and Kohat areas and middle parts of north Indus like Nathiagali-Abbottabad section, however not developed or eroded during tectonic phases in the eastern part like Kotli-Tatta Pani section. The upper Jurassic Samanasuk limestones were the host of tracks and trackways of dinosaurs (Figure 2). 


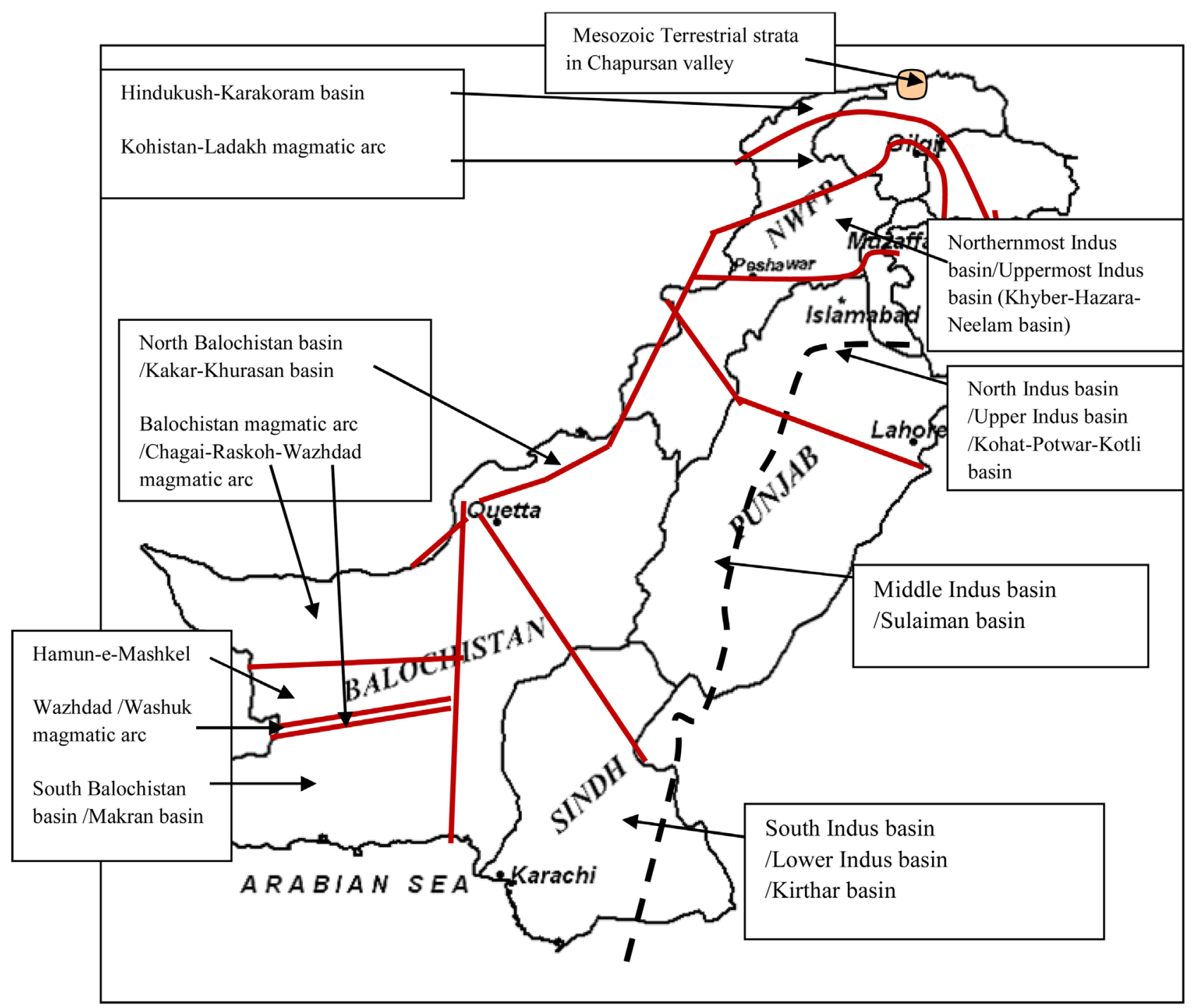

Figure 1. Basin architectures and configurations of Pakistan during Jurassic-Cretaceous (J-K) and Cretaceous-Paleogene (K-Pg) transition periods. The red coloured thick lines show boundaries of basin/sub-basins. The black fine continuous lines show boundaries of country Pakistan and its provinces. The black dashed line show generalized Paleo Sea line during the Jurassic and Cretaceous periods, Tethys Sea was on the western part of Indus basin (a part of Gondwana lands) on the west of this dashed line, and Terrestrial land was on the east of this dashed line. North direction is upward.

The Jurassic strata of middle Indus foldbelt are represented by Jurassic Loralai and Chiltan limestones. The Jurassic-Cretaceous transition (Figure 2) is well exposed in the western part of middle Indus foldbelt like Loralai area (Gadebar and Daman Ghar ranges), Quetta area (Chiltan, Murdar and Takatu mountains), Ziarat, Qila Saifullah and Zhob districts areas while in the northeastern part of middle Indus foldbelt like Musa Khel (Shin Ghar range) and Shirani (Dhana Sar-Takht Sulaiman range) districts. In the Loralai and surrounding areas the Jurassic-Cretaceous transition is well known as brown weathered shale and limestone of Dilband Formation. In a few section of Murdar Ghar (Quetta-Bolan), this transition is also hosted by a few thin lense of ironstone. While in other areas of middle Indus foldbelt, this transition is grey shale alternated by thin beds 

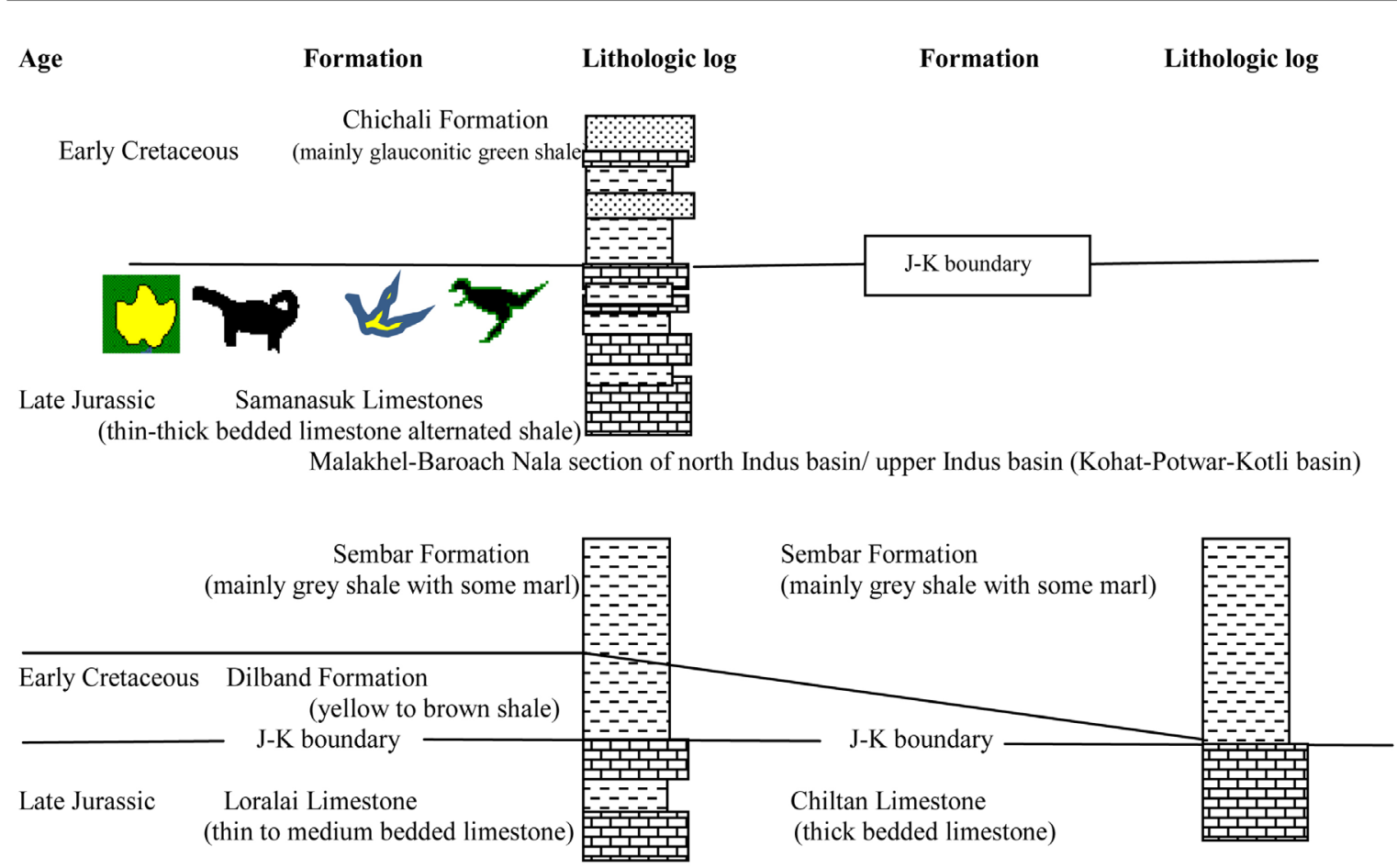

Southern part of middle Indus foldbelt (Loralai area) (Karkh-Kharzan area)

Southern part of South Indus foldbelt /lower Indus foldbelt

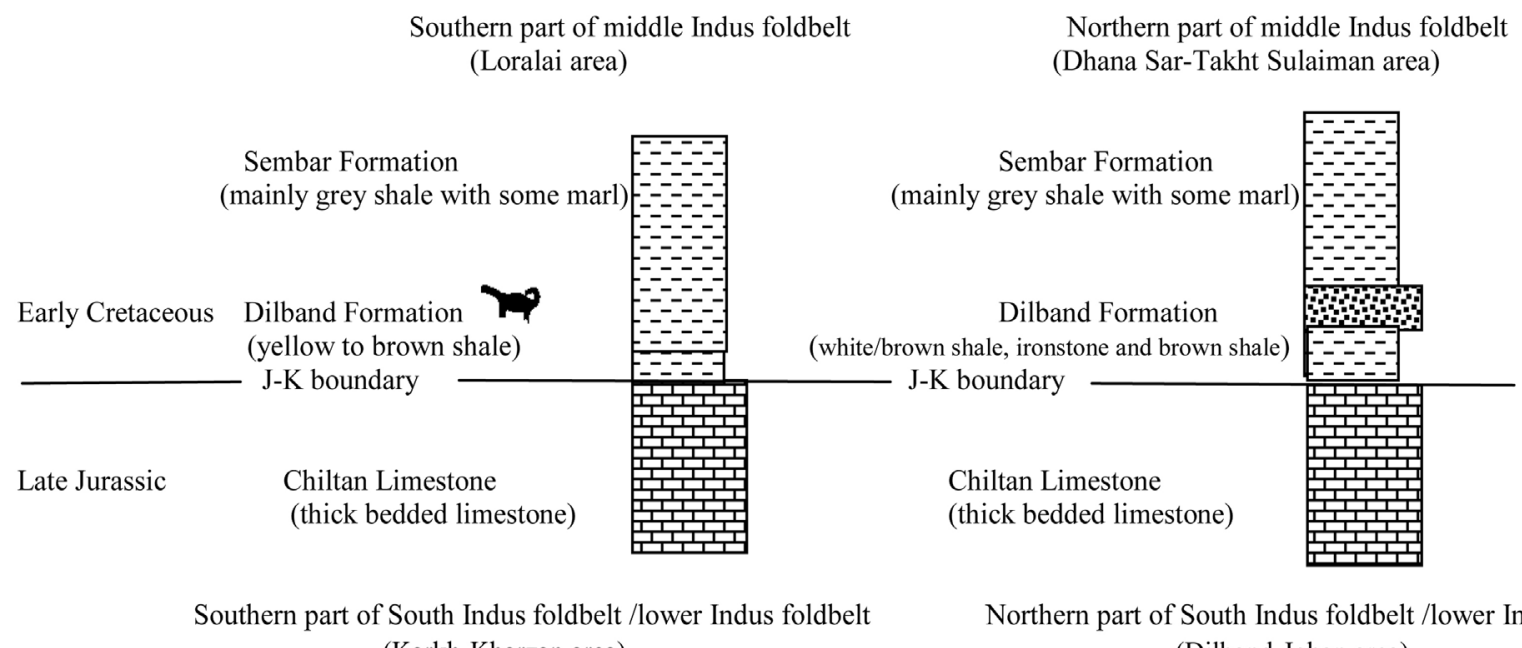

Northern part of middle Indus foldbelt (Dhana Sar-Takht Sulaiman area)
Northern part of South Indus foldbelt /lower Indus foldbelt (Dilband-Johan area)

Figure 2. Upper sequence log, Jurassic-Cretaceous boundary and transition in North Indus basin (Kohat-Potwar-Kotli basin). Middle sequence log, Jurassic-Cretaceous boundary and transition in southern and northern part of middle Indus foldbelt (Sulaiman foldbelt). Lower sequence log, Jurassic-Cretaceous boundary and transition in southern and northern part of south Indus foldbelt (Kirthar foldbelt). Not on scale. Symbols in caption of Figure 3.

of limestone/marl.

The Jurassic strata of south Indus foldbelt are represented by Jurassic Anjira and Chiltan (Zidi) limestones. The Jurassic-Cretaceous transition (Figure 2) is well exposed in the western part of south/lower Indus foldbelt like Khuzdar Mula/Moola-Zahri ranges, Kalat and Mastung (Dilband, Maran and adjoining ranges), Quetta-Bolan districts (Chiltan-Murdar Ghar ranges). In the Dilband and adjoining areas just south of Quetta, the Jurassic Limestone is followed by Jurassic-Cretaceous transitional laterite, iron stone and vary colored shale of Dilband 


$\begin{array}{llll}\text { Age } & \text { Formation } & \text { Fithologic log } & \text { Fithologic log }\end{array}$

Early Paleocene $\begin{gathered}\text { Hangu Formation } \\ \text { (sandstone, shale and coal) } \\ \text { K-Pg boundary }\end{gathered}$
$\begin{gathered}\text { Latest Cretaceous } \\ \text { (laterite/bauxite, sandstone and shale) }\end{gathered}$

Western part of north Indus basin (Kohat area)

Eastern part of north Indus basin (Tatta Pani, Kotli area)

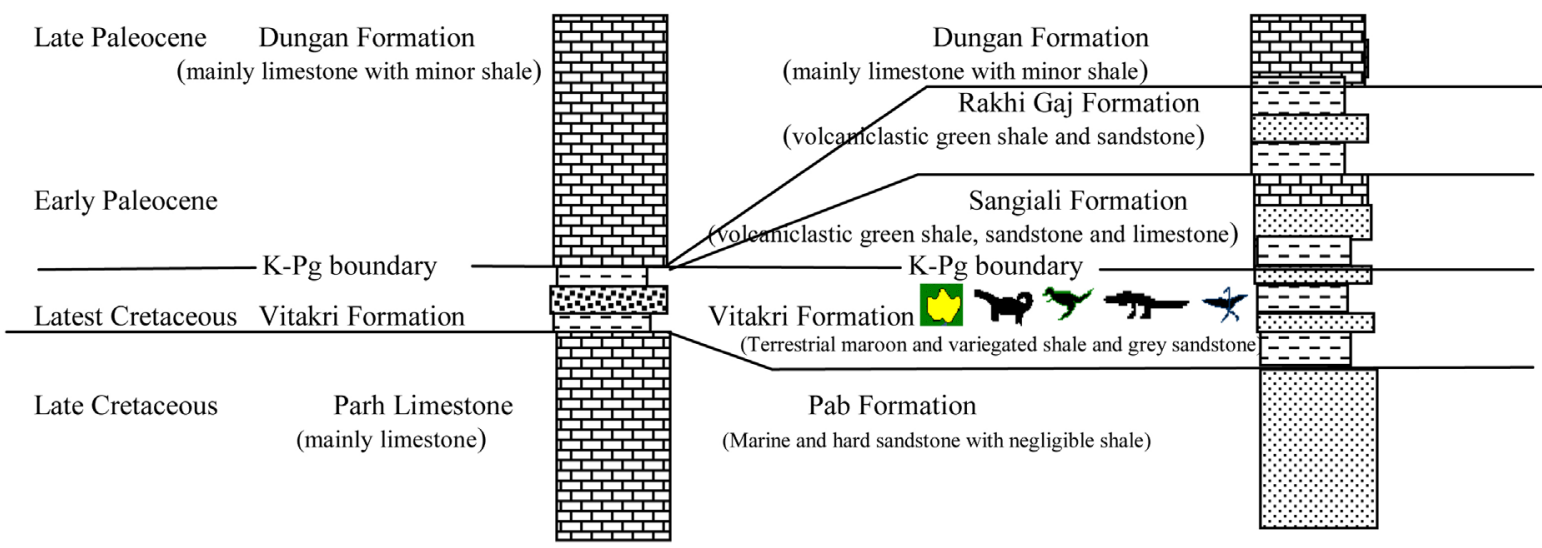

Western part of middle Indus basin (Ziarat and surrounding area) Eastern part of middle Indus basin (Vitakri and surrounding area)

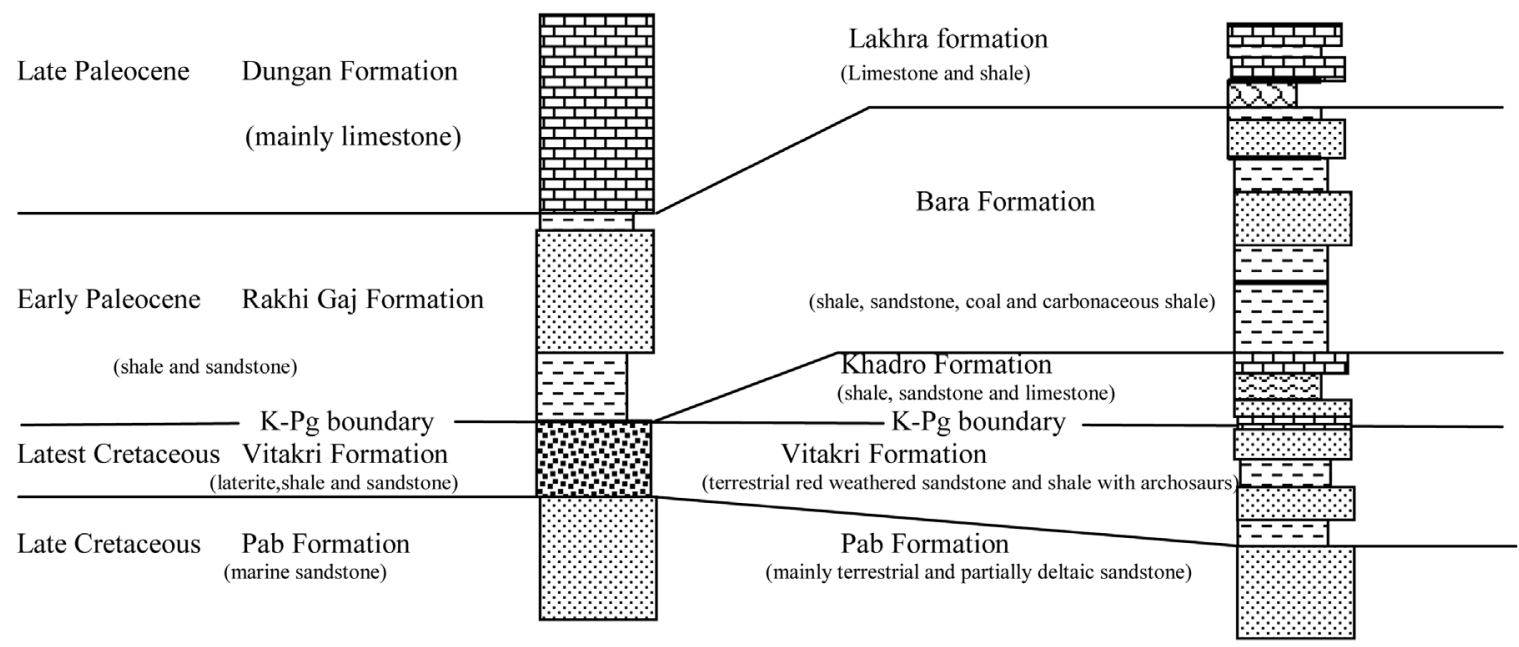

Western part of south Indus foldbelt (Kharzan area) Eastern part of south Indus foldbelt (Bara/Khadro and southern core areas of Laki anticlir

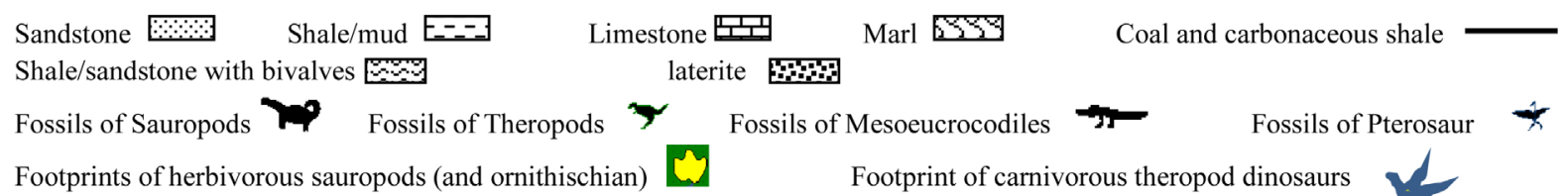

Figure 3. Upper sequence log, Cretaceous-Paleogene boundary and transition in western and eastern part of north Indus basin. Middle sequence log, Cretaceous-Paleogene boundary and transition in western and eastern part of middle Indus foldbelt (Sulaiman foldbelt). Lower sequence log, Cretaceous-Paleogene boundary and transition in western and eastern part of south Indus foldbelt (Kirthar foldbelt). Not on scale.

Formation and further followed by Early Cretaceous Sembar shale. This lithology is maximum thick in the Dilband mountain while diminish in the adjoining 
areas. The Jurassic of Moola-Zahri range is represented by many diverse fauna [4]. This Jurassic-Cretaceous transition is also the host of titanosauriforms/titanosaurs (Figure 2).

\subsection{Cretaceous/Paleogene Transition in Pakistan, Its Distribution and Lithological Variations}

Indus basin of Pakistan is located east of Balochistan basin, south of KohistanLadakh magmatic arc and Karakoram basins, west of Ganges and Indo-Pakistan shield and north of Indo-Pakistan Ocean and Arabian Sea (Figure 1). The Pab Formation is significant due to hosting of footprints and tracks in Zhob division of Balochistan. The Vitakri Formation is significant due to hosting of well dominated and diversified latest Maastrichtian archosaurs (Figure 3). The latest Maastrichtian strata is represented by two fluvial claystone/shale units, each caped by sandstone unit of Vitakri Formation [5] [6] widely exposed in middle Indus basin. The Pab Formation was divided into three members as Dhaola, Kali and Vitakri [5]. Later on the Vitakri member (upper) of Pab Formation was upgraded as Vitakri Formation [6]. The strata of Cretaceous-Paleogene transition is well exposed [5] [7] [8] [9] in north, middle and south Indus basins (Figure 3) while it is negligible in all other regions. The Indus basin is very significant due to hosting wide and variable lithologies of Cretaceous-Paleogene transitions. The northernmost Indus basin consists of mostly igneous and metamorphic rocks. The north Indus consists of Precambrian to recent strata while the middle and south Indus basins consist of Mesozoic and Cenozoic strata. The correlation of $\mathrm{K}-\mathrm{Pg}$ transitional sequence in different parts of Indus basin is shown in (Figure 3) and here details of north, middle and south Indus basins are provided.

\subsubsection{Cretaceous-Paleogene Boundary in the North Indus (Kohat-Potwar-Kotli) Basin of Pakistan, Its Distribution and Lithovariations}

The north Indus basin consists of many Cretaceous and Paleocene formations besides other older and younger units. The southern part of north Indus basin consists of green shale rarely varied colored, and green sandstone of lower Cretaceous Chichali Formation while white sandstone of upper Cretaceous Lumshiwal Formation, and lateritic and bauxitic unit of Indus Formation in the southern part. The northern part of north Indus basin consists of green shale rarely varied colored and green sandstone of lower Cretaceous Chichali Formation caped by thin sequence of white sandstone of upper Cretaceous Lumshiwal Formation, thick sequence of limestones of Kawagarh Formation and thin sequence of laterite and bauxite of Indus Formation. The marine Kawagarh limestone is missed in the southern part due to common terrestrial and deltaic environment. The north Indus basin consists of shale, sandstone and coal and carbonaceous shale of Early Paleocene Hangu Formation, relatively fine nodular limestones of Lockhart Formation (than the coarse nodular limestones of Eocene Sakesar or Margala Hill limestones). The K-Pg transition is represented by the 
contact of Maastrichtian Indus Formation (laterite, bauxite and red to maroon beds), and Danian Hangu Formation (grey shale and sandstone with coal and carbonaceous shales) (Figure 3). So here the red colored sequence of End Cretaceous Indus Formation transitionally shifted into grey shale and sandstone and coal and carbonaceous shales of Early Paleocene Hangu Formation. This K-Pg transition is well exposed in southern limb of north Indus basin like Katha Khoshab, eastern Salt Range and Tatta Pani Kotli areas and surroundings, and in northern limb of north Indus basin like Hangu-Cherat Range and surrounding areas of Kohat and Surge area of Attock, Nathiagali and surrounding areas of Sothern Hazara, and Muzaffarabad area. Here the varied colored and oolitic to pisolitic bauxite and laterite, ferruginous sandstone, siltstone and muds/shales/clays of latest Cretaceous Indus Formation varied in thickness from a few meter $/ \mathrm{m}$ to about 10 meters $/ \mathrm{m}$ while the grey to green and varied colored shale, grey sandstone, coal and carbonaceous shale of Early Paleocene (Danian) Hangu Formation varied in thickness from $15 \mathrm{~m}$ to about $150 \mathrm{~m}$. It is necessary to mention that Indus Formation is based on different aged older rocks of Mesozoic, Paleozoic and Precambrian. The laterite and bauxite of Indus Formation is assumed as lacustrine to estuaries deposits. In general the Cretaceous strata are commonly hosted by archosaurian reptile bones [10] [11] [12] [13] and footprints [4] and belemnite while Paleocene strata are hosted by nautiloids.

\subsubsection{Cretaceous-Paleogene Transition in the Middle/Central Indus (Sulaiman) Basin of Pakistan, Its Distribution and Lithological Variations}

The middle Indus basin consists of many Cretaceous and Paleocene formations besides other older and younger units. The Sembar (dominantly grey shale), Goru (shale and marl), Mekhtar (sandstone) and Parh (limestone) formations of lower Cretaceous Parh Group, and Mughal Kot (shale, sandstone and rare limestone), Fort Munro (limestone), Pab Sandstone and Vitakri (maroon to red and varied colored shale/muds and grey to white sandstones) formations of upper Cretaceous Fort Munro Group. These Cretaceous strata are common and thick in the eastern part of Sulaiman foldbelt and also relatively less thick in the western part of Sulaiman foldbelt. The Paleocene strata in the middle Indus is represented by Danian Sangiali (green shale and sandstone and grey to brown limestone), Early-Middle Paleocene Rakhi Gaj (green shale and sandstone and hematitic low grade ironstone in the upper part) and upper Paleocene Dungan (limestone with rare shale varied lithology at different sections) formations. The eastern part of middle Indus basin is covered by plain areas and Cholistan desert of South Punjab (Saraikistan or Saraiki Province) while the western part of middle Indus basin is represented by well exposed and folded rocks commonly called as Sulaiman foldbelt located under the territory of Balochistan and South Punjab. The K-Pg transition is represented by maroon to red and varied colored shale alternated by two sandstone units of end Cretaceous Vitakri Formation and green shale and sandstone and grayish brown limestone of Early Paleocene Sangiali 
Formation in the Vitakri and surrounding areas (Figure 3). While in other areas of middle Indus basin, the green shale and sandstone of Rakhi Gaj Formation is widely distributed which is capped on Vitakri Formation where it is developed or Pab Formation where Vitakri Formation is not developed. The lower shale unit of Vitakri Formation is caped on Pab Sandstone. The uppermost sandstone unit is capped by Danian green shale, sandstone and greyish brown limestone. Further in the north the Kingri and Alu Khan (Gharwandi) areas of Musa Khel district of Balochistan this Vitakri Formation is represented by two carbonaceous shale units alternated and caped by sandstone units. Westward in Ziarat and Sor Kach Tangi area (near the Mina area) of Zhob district, the 1 - 5 m laterite is dominant unit representing Vitakri Formation.

\subsubsection{Cretaceous-Paleogene Transition in the South/Lower Indus (Kirthar) Basin of Pakistan, Its Distribution and Lithological Variations}

In the south Indus basin the Mesozoic and especially Cretaceous strata is same as middle Indus basin. Only difference is found in the Cenozoic rocks. In eastern Kirthar foldbelt, the K-Pg transition is represented by the contact of Maastrichtian Vitakri Formation (about 35 - 50 m thick red weathered sandstone with subordinate shale of terrestrial fluvial origin hosting reptile and fish bones) and the Danian Khadro Formation (green shale, sandstone, limestones and volcanics) in the core of thrusted Laki anticline (eastern Kirthar range) caped by Bara Formation (shale and sandstone with coal and carbonaceous shale) and Lakhra Formation (mainly limestone with subordinate shale well exposed in Lakhra anticline) (Figure 3). In the western Kirthar ranges, the K-Pg boundary is represented by the contact of Maastrichtian Vitakri Formation (only a few centimeter to 30 centimeter thin and discontinuous exposure of laterite host Pakiring kharzani bivalve ) and the Early Paleocene Rakhi Gaj Formation (shale, sandstone and volcaniclastic dark grey to green sandy beds hosting nautiloids well exposed in the western bank of north south trending major streams located just $5 \mathrm{~km}$ east of Karkh town) and Dungan Formation (mainly limestone with subordinate shale). This volcaniclastic dark grey sandstone beds (host nautiloids) of Danian Rakhi Gaj Formation is the westernmost extension of Deccan Volcanic Group in Pakistan. In the Bara and Khadro Nai/nalas and its southern extension in the core of Laki thrusted anticline (Jamshoro district of Sindh) of eastern Kirthar range the red and brown weathering sandstone and shale of Vitakri Formation which is thrusted on younger strata.

\subsection{Titanosauriformes (Brohisaurus kirthari) from Pakistan}

Brohisaurus is the only one Titanosauriformes reported from the Kirthar basin (Figure 1) of Pakistan while Gspsaurus [11], Saraikimasoom [12], Pakisaurus [13] and Sulaimanisaurus [13] were found from the Sulaiman basin (Figure 4).

\section{Systematic paleontology:}

Dinosauria [14]; 


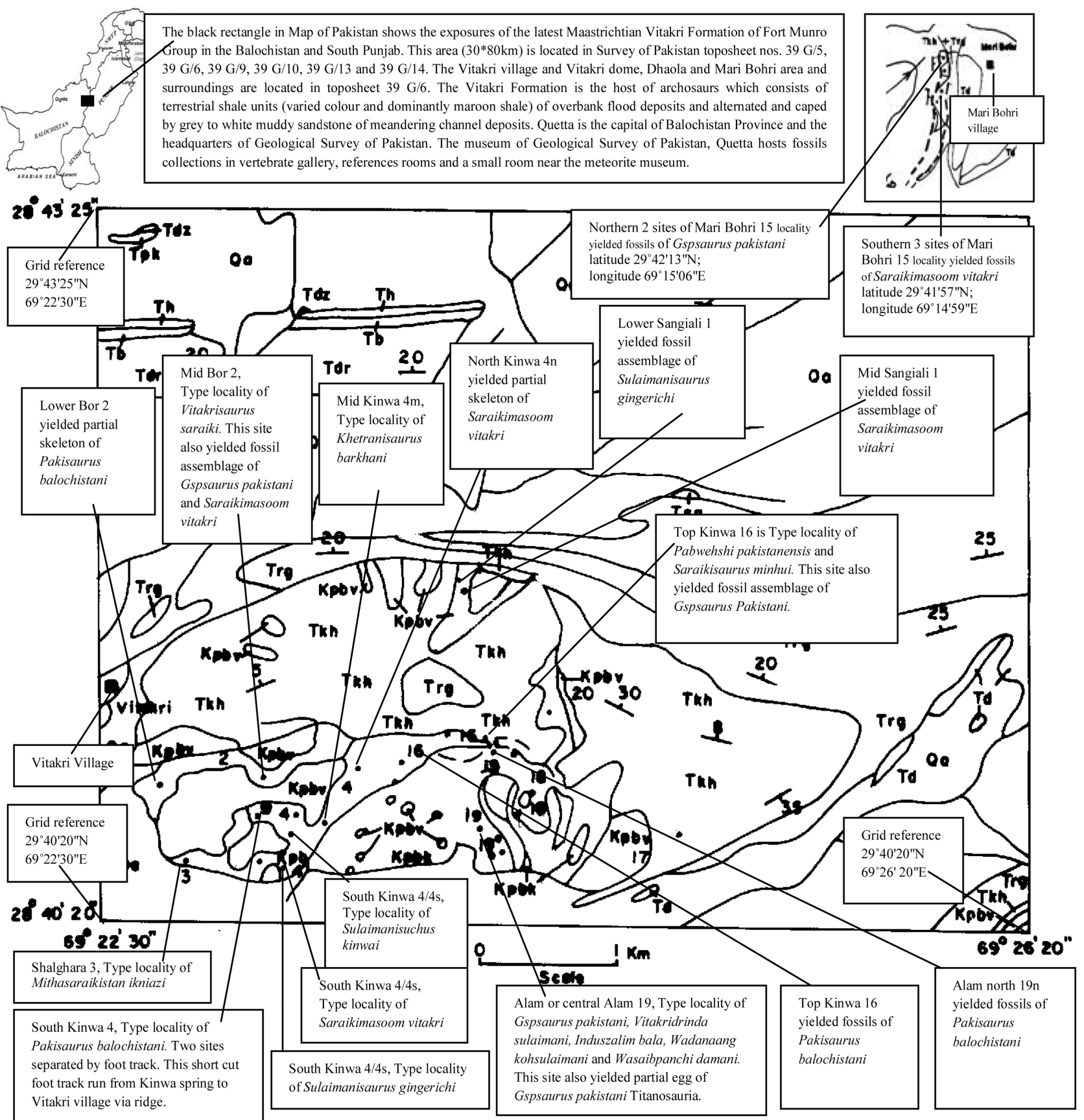

Figure 4. Upper right map, Black rectangle in Map of Pakistan shows the exposures of latest Maastrichtian Vitakri Formation in Vitakri and surrounding areas which host 25 localities of archosaurs fossils in eastern Sulaiman fold and thrust belt (commonly called as Sulaiman foldbelt), eastern Balochistan and western Saraikistan (South Punjab). Upper left map, small black circle in geological map of Mari Bohri locality 15 show fossil assemblage sites (complete map can be seen in [6]). Lower map, Geological map of Vitakri Dome area showing archosaurs localities, Barkhan District, Balochistan Province, Pakistan. The numerical number represents localities number (except the dip number perpendicular to strike). 1, Sangiali; 2, Bor; 3, Shalghara; 4, Kinwa; 16, Top Kinwa, 17, Dada Pahi; 18, eastern Alam; 19, Alam; 20, Rosmani. The black square near the western extremity of map area shows village of Vitakri ( $29^{\circ} 41^{\prime} 19^{\prime \prime} \mathrm{N}$ latitude, $69^{\circ} 23^{\prime} 02^{\prime \prime E}$ longitude). The small black circle shows the site of fossil assemblages. Abbreviation; Qa, Alluvium; Tdz, Drazinda Formation. Tpk, Pirkoh Formation. Tdm, Domanda Formation. Thr, Habib Rahi Formation. Tb, Baska Formation. Tdr, Drug Formation. Tsg, Shaheed Ghat Formation. Td, Dungan Formation. Trg, Rakhi Gaj Formation. Tkh, Sangiali Formation. Kpbv, Vitakri Formation. Kpbk, Kali member of Pab Formation. Kpbd, Dhaola member of Pab Formation. Map of Vitakri dome is modified after [6]. Scale bar is equal to 1 kilometer. 
Saurischia [15];

Sauropoda [16];

Titanosauriformes [17];

Brohisaurus kirthari [10].

(Figure 5)

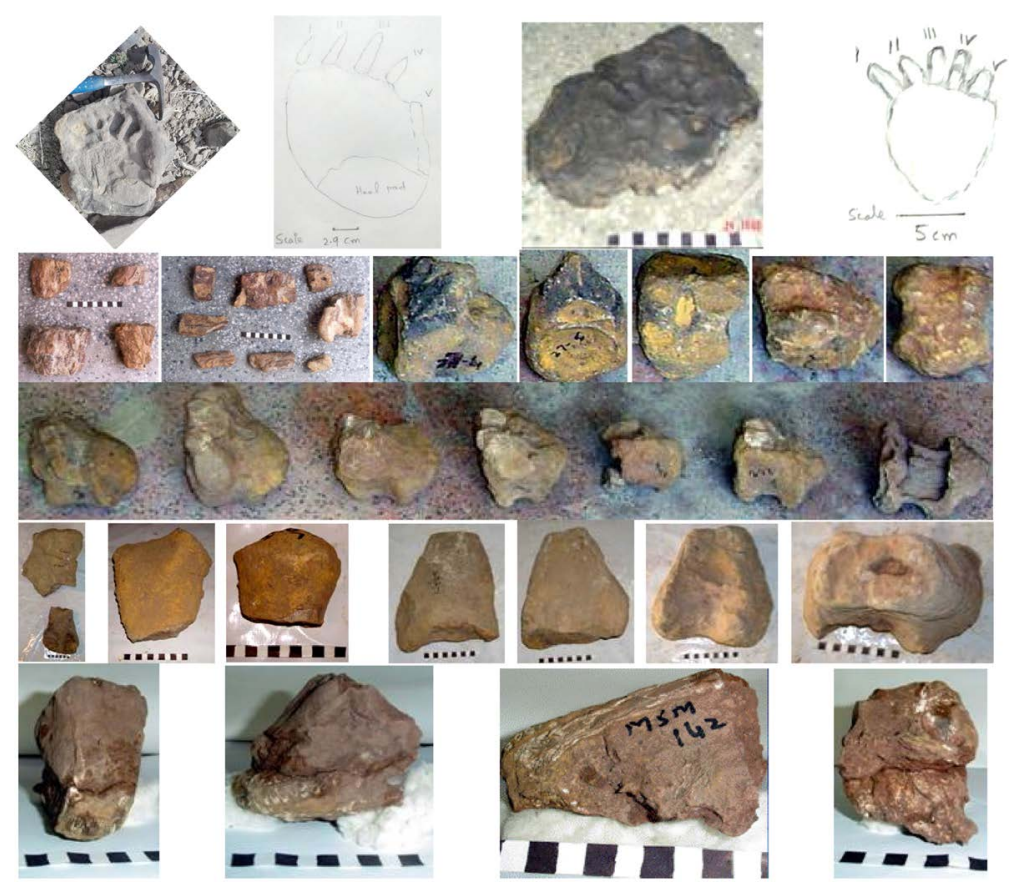

Figure 5. Row 1, Image and line drawing of a pes footprint natural cast of Dgkhansaurus maarri titanosaurian sauropod collected from southernmost extremity/plunge of Fort Munro anticlinorium (see in Figure 1(c) of [6]) and a pes footprint of Chiltanpaer nicki Titanosauriformes found from Mula area (see in Figure 5 of [7]). Row 2, photo 1,2/p1,2, Brohisaurus kirthari holotypic fossils found from Sun Chaku locality (see in Figure 1 of [10]), Khuzdar district, except GSP/MSM-96-K which is referred found from Lakha Pir Charo (see in Figure 1 of [10]), Khuzdar district; p1, top row, femur parts GSP/MSM89-K, GSP/MSM-102-K; lower row, femur cross sections GSP/MSM-86-K, GSP/MSM-91$\mathrm{K}$; p2, top row, rib cross sections GSP/MSM-92-K, GSP/MSM-87-K, GSP/MSM-94-K; mid row, distal rib GSP/MSM-93-K, proximal fibula GSP/MSM-88-K; lower row, neural spine GSP/MSM-95-K, neural spine GSP/MSM-96-K; osteoderm ellipsoidal tubule GSP/ MSM-98-K. P3-P7, Khetranisaurus barkhani holotypic two caudal vertebrae GSP/MSM27-4 in 3 views and GSP/MSM-28-4 in 2 views found from mid Sangiali $4 \mathrm{~m}$ type locality (Figure 4), Barkhan district. Row 3, Sulaimanisaurus gingerichi holotypic seven caudal vertebrae GSP/MSM-17(a)-4, GSP/MSM-18-4, GSP/MSM-19-4, GSP/MSM-20-4, GSP/ MSM-21-4, GSP/MSM-21(a)-4, GSP/MSM-22-4 in laterodorsal views collected from south Kinwa 4 (Figure 4), Barkhan district. Row 4, Sulaimanisaurus gingerichi referred fossils like flattened tibia GSP/MSM-235-7, fibula GSP/MSM-253-7 and metatarsal GSP/MSM-296-7 collected from Basti nala Zubra peak 7 locality (see locality 7 in Figure 1(c) of Dhaola anticlinorium [6]) of Barkhan district, and distal humerus GSP/MSM262-1 in anterior and posterior views and distal femur GSP/MSM-232-1 in 2 views found from lower Sangiali 1 (Figure 4) of Barkhan district. Row 5, Saraikimasoom vitakri holotypic snout GSP/MSM-142-4 in 4 views found from south Kinwa 4 or 4s (Figure 4), Barkhan district, Balochistan, Pakistan. Scale each black or white digit is $1 \mathrm{~cm}$. MSM is the abbreviation for the name of collector M. Sadiq and its tribe Malkani. 
Holotype: Femur cross sectional parts GSP/MSM-86-K, GSP/MSM-89-K, GSP/ MSM-91-K and GSP/MSM-102-K; rib cross sections GSP/MSM-92-K, GSP/MSM87-K and GSP/MSM-94-K; distal rib cross section GSP/MSM-93-K; proximal fibula GSP/MSM-88-K; neural spine GSP/MSM-95-K; and armor osteoderm ellipsoidal tubule GSP/MSM-98-K (Figure 5). Holotypic fossils were found within $5 \mathrm{~m}$ diameter as surface finds in the same formation, same locality, no duplication and fit size seem to be associated as a single individual. These fossils are housed in the museum of Geological Survey of Pakistan, Quetta.

Referred specimen: Neural spine GSP/MSM-96-K (Figure 5), housed in the museum of Geological Survey of Pakistan, Quetta.

Horizon, Age and locality: Lower clay/shale horizon of latest Jurassic-Earliest Cretaceous Sembar Formation of Sun Chakku type Locality, Karkh area, Khuzdar district, Baluchistan, Pakistan. The grid reference of the Sun Chaku type locality are latitude $27^{\prime} 50^{\prime} 40^{\prime \prime} \mathrm{N}$; longitude $67^{\prime} 09^{\prime} 66^{\prime \prime} \mathrm{E}$, and Lakha Pir Charo referred fossil locality are latitude $27^{\prime} 37^{\prime} 35^{\prime \prime} \mathrm{N}$; longitude 67"02'10"E as shown in Figure 1 of [10].

Diagnosis: The Brohisaurus kirthari share with Titanosauriformes (Sauropoda) as elliptical femoral cross section and pneumatic cavities in the ribs. The Brohisaurus kirthari characterized simple slightly convexo-convex (biconvex) ribs; well developed scar on proximal fibula for attachment of tibia; single neural spine (not bifid); tube like relatively small ellipsoidal armor osteoderm while $S a$ raikimasoom vitakri has small and also large ellipsoidal osteoderm [12] and Gspsaurus pakistani has mosaic type platy and also ellipsoidal osteoderm [11].

Description: Its osteoderm is relatively small than the ellipsoidal osteoderms of latest Maastrichtian Saraikimasoom Vitakri. The armor osteoderm preserved length is $6 \mathrm{~cm}$ and maximum width is $3.5 \mathrm{~cm}$. In general it is tube like ellipsoidal. The other materials are well described in [10]. Neural spine is single (not bifid). Further its other aspects and description of materials (except armor osteoderm which is described above) were reported in [10].

\subsection{Titanosaurian Sauropods from Pakistan}

The four titanosaur taxa like Gspsaurus pakistani [11] and Saraikimasoom vitakri [12] of stocky poripuchian titanosaurs and Pakisaurus balochistani [13] and Isisaurus colberti [13] of slender poripuchian titanosaurs were recognized out of the total 9 titanosaur taxa from the latest Maastrichtian terrestrial Vitakri Formation of Pakistan and coeval 6 titanosaur taxa from India [11] [12] [13].

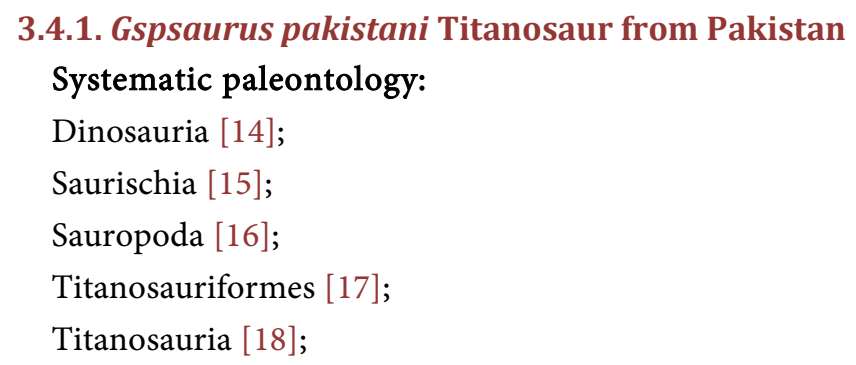


Poripuchia new taxon.

Etymology: Pori, Urdu and Saraiki language mean complete, puchia or puch, Saraiki word for tail. For general understanding procoelous complete tail.

Definition: Pakisaurus, Sulaimanisaurus, Isisaurus, Gspsaurus, Saraikimasoom, Balochisaurus, Marisaurus, Maojandino, their most recent common ancestor and all of its descendants.

Diagnosis: Poripuchia is a subgroup of Titanosauria which characterized all procoelous caudals including the distalmost caudals, however in some taxa the first caudal is biconvex (while lithostrotian lack procoely in distalmost caudals).

Included species: Pakisaurus balochistani, Sulaimanisaurus gingerichi, Isisaurus colberti, Gspsaurus pakistani, Saraikimasoom vitakri, Balochisaurus malkani and Marisaurus jeffi.

1) Gspsauridae new family

Definition: Gspsaurus, Marisaurus, Maojandino, Balochisaurus, Nicksaurus, Saraikimasoom; their most recent common ancestor and all of its descendants.

Included species: Gspsaurus pakistani, Marisaurus jeffi, Maojandino alami, Balochisaurus malkani, Nicksaurus razashahi and Saraikimasoom vitakri.

Diagnosis: Gspsauridae major differentiation characters from Pakisauridae are as U-shaped anterior upper jaw profile, anterior dentary rounded (no chin forming), highly vascularised and pneumatic rostrum and dentaries bones, broad reversed $\mathrm{V}$-shaped ventral palatal processes laterally attached to upper maxillary ramus or upper jaw ramus, while dorsally attached to dorsal palatal process junction, $\mathrm{V}$-shaped dorsal palatal hook attached on the contact of maxilla and premaxilla on both sides, slender and circular to slightly oval teeth with slender indices 3 - 5; conical and pointed teeth converge and taper on all sides from base toward tip (opposite of pakisaurids teeth which have almost same thickness except tip); ratio of mid transverse width above and below of mid caudal centrum varies from 1 to 2 , the ventral view of mid caudal centra are strongly compressed, stocky tibia; proximal view of proximal stocky tibia circular to oval shaped (as opposite in Pakisauridae the flattened shaped proximal tibia), distal tibia is transversely more wide than anteroposteriorly width or distal tibia is anteroposteriorly less wide than transverse width (as opposite in Pakisauridae distal tibia is anteroposteriorly more wide than transverse width).

2) Gspsaurinae new subfamily

Definition: Gspsaurus, Marisaurus, Maojandino; their most recent common ancestor and all of its descendants.

Included species: Gspsaurus pakistani, Marisaurus jeffi and Maojandino alami.

Diagnosis: Gspsaurinae is a subgroup of Gspsauridae (least inclusive clade of Gspsauridae) containing Gspsaurus pakistani but not Saraikimasoom vitakri. Gspsaurinae major differentiation features from Saraikimasoominae are as V shaped anterior dentaries symphyses profile or $\mathrm{V}$ shaped anterior junction of dentary rami (while Saraikimasoominae have broad U-shaped anterior junction of dentary ram); dentary symphysis and its orientation is angled $15^{\circ}$ or more anteriorly to axis of jaw ramus (while opposite, Saraikimasoominae have dentary symphy- 
sis and its orientation as vertical or perpendicular to axis of jaw ramus); relatively large sized skull (while Saraikimasoominae have relatively small sized skull); relatively large, more slender, recurved conical, circular to slightly oval teeth (while Saraikimasoominae have relatively robust, small, slightly recurved conical, and circular to slightly oval teeth); relatively large size (in thickness, width and length) dentary rami (while Saraikimasoominae have relatively small size dentary rami); ventral view of mid caudal centra compressed, mid caudal centra with the ratio of mid transverse width above and below varies from 1 to 1.5 (while Saraikimasoominae have significantly reduced ventral view of mid caudal centra, mid caudal centra with the ratio of mid transverse width above and below varies from 1.5 to 2); and Gspsaurinae have relatively large sized stocky proximal tibia which have more anteroposterior width than transverse width (while Saraikimasoominae have relatively large sized stocky proximal tibia which have equal transverse and anteroposterior width on proximal view).

3) Gspsaurus new genus

Type and only known species: Gspsaurus pakistani, new species;

Type locality, horizon and age: As for type and only species;

Diagnosis: See diagnosis for type and only species below;

Etymology: The genus name Gspsaurus honors the Geological Survey of Pakis$\tan$ (GSP) and saurus, Greek meaning lizard. Its pronunciation is G.S.P.saurus.

4) Gspsaurus pakistani new species

(Figure 6)

Etymology: The species name pakistani honors the host country Pakistan.

Holotype: Snout and associated skull materials GSP/MSM-79-19 and GSP/ MSM-80-19; braincase along with articulated occipital condyle GSP/MSM-62-19; cervical vertebrae GSP/MSM-107-19, GSP/MSM-108-19, GSP/MSM-109-19 GSP/MSM-437-19, GSP/MSM-220-19 and GSP/MSM-502-19; dorsal vertebrae GSP/MSM-110-19, GSP/MSM-111-19 and GSP/MSM-112-19 and GSP/MSM617-19; caudal vertebrae GSP/MSM-113-19, GSP/MSM-114-19, GSP/MSM115-19, GSP/MSM-116-19, GSP/MSM-117-19, GSP/MSM-218-19, GSP/MSM219-19, GSP/MSM-221-19, GSP/MSM-696-19 and GSP/MSM-777-19; vertebral process GSP/MSM-146-19; left and right partial distal scapula GSP/MSM-110019, GSP/MSM-217-19; proximal radius GSP/MSM-215-19; partial ilia GSP/MSM216-19; proximal left femur GSP/MSM-213-19; distal left femur GSP/MSM-11819; proximal left tibia GSP/MSM-119-19; distal left tibia GSP/MSM-569-19; and distal right tibia GSP/MSM-710-19 (Figure 6). It can be seen in Figures 1-4 of [11]. This holotype is the best preserved and also the one with the largest amount of diagnostic features. The holotypic snout and associated posterior skull and postcrania consists of articulated upper and lower jaws with teeth, palatal processes, palatal bones like posterior vomerine, fused palatine and pterygoid, and associated left quadrate, partial quadratojugal and possibly lowermost portion of squamosal, braincase including decurved and much taller left and right Paroccipital processes and broad occipital condyle, cervical, dorsal and caudal vertebrae, and neural arches, left and right scapulae, sternal plate or ilia, radius, left femur, left 


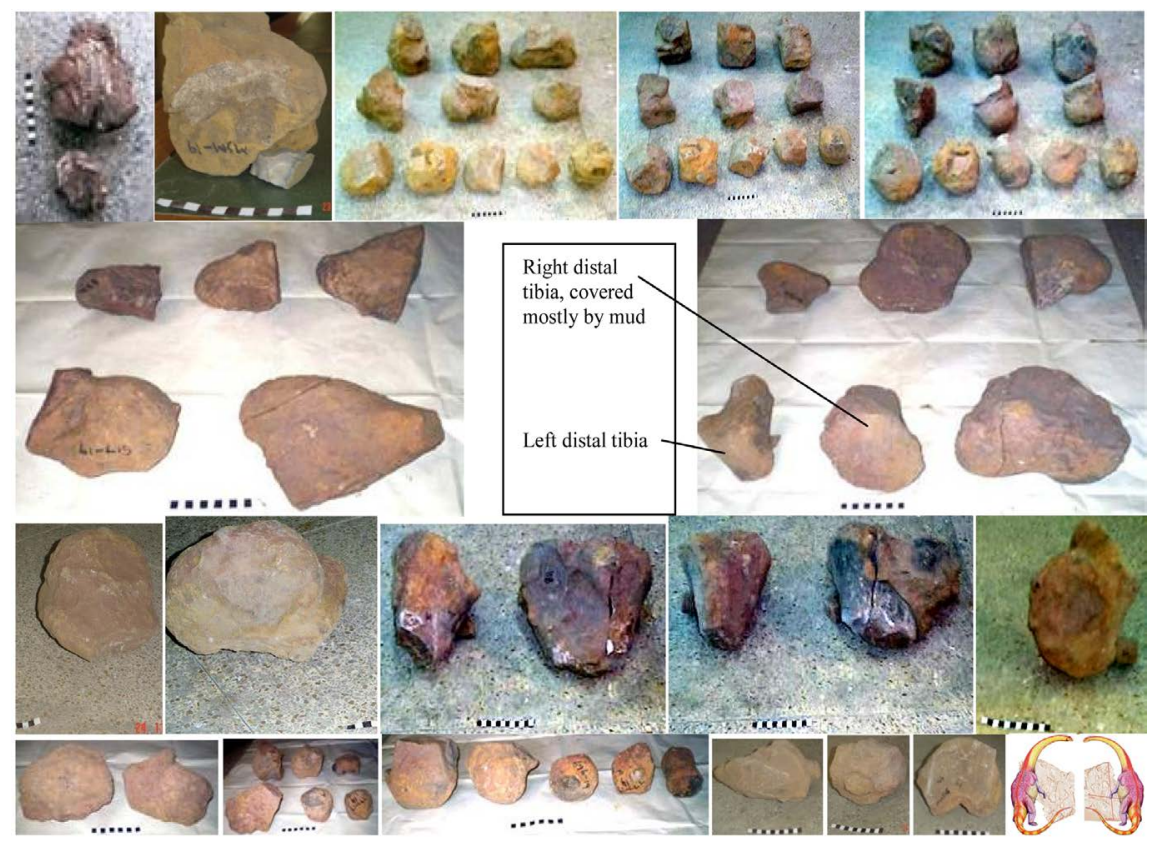

Figure 6. Gspsaurus pakistani holotype (rows 1, 2, 3 and 4 except the last 2 photos of models) found from Alam 19 type locality (Figure 4), Barkhan district, Balochistan Province, Pakistan [11]. Row 1, p1, skull 2 pieces GSP/GSP/MSM-79-19, GSP/MSM-80-19; p2, braincase GSP/MSM-62-19 in anterior view; $\mathrm{p3}, 4,5$, subrow 1, cervical vertebrae GSP/MSM107-19, GSP/MSM-108-19, GSP/GSP/MSM-109-19; subrow 2, dorsal vertebrae GSP/MSM110-19, GSP/MSM-111-19, GSP/MSM-112-19; subrow 3, caudal vertebrae GSP/MSM113-19, GSP/MSM-114-19, GSP/MSM-115-19, GSP/MSM-116-19, GSP/MSM-117-19. Row 2, p1, subrow 1, cervical vertebrae GSP/MSM-437-19, GSP/MSM-220-19, GSP/MSM502-19; subrow 2, dorsal vertebra GSP/MSM-617-19, partial ilia/sternal GSP/MSM-216-19; p2, subrow 1, proximal radius GSP/MSM-215-19; proximal left tibia GSP/MSM-119-19; proximal left femur GSP/MSM-213-19; subrow 2, distal left tibia GSP/MSM-569-19; distal right tibia GSP/MSM-710-19; distal left femur GSP/MSM-118-19. Row 3, p1,2, proximal left tibia GSP/MSM-119-19; p3,4, distal right tibia GSP/MSM-710-19 and distal left femur GSP/MSM-118-19 in 2 views; p5, transversely elongated oval shaped right distal tibia GSP/MSM-710-19 in ventral view; Row 4, p1, left and right partial distal scapula GSP/ MSM-1100-19, GSP/MSM-217-19; p2, subrow 1, caudal vertebrae GSP/MSM-219-19, GSP/ MSM-218-19 and GSP/MSM-221-19; subrow 2, partial distal right scapula GSP/MSM-21719; caudal vertebrae GSP/MSM-696-19, GSP/MSM-777-19; p3, caudal vertebrae GSP/ MSM-219-19, GSP/MSM-218-19, GSP/MSM-696-19, GSP/MSM-777-19, GSP/MSM-22119; p4,5,6, vertebral process/neural arch GSP/MSM-146-19 in 3 views; p7,8, Gspsaurus models managed by British Journalist Nicholas Allen and prepared by Russian Paleoartist Dr. Dmitry Bogdanov. Scale, Each black or white digit is $1 \mathrm{~cm}$.

and right tibia. This holotype was found as two assemblages. The holotype skull materials GSP/MSM-79-19 and GSP/MSM-80-19 found as fragmentary close to with each other just within a 1 - 2 meter distance and seems to be associated because found same time in the same locality and same formation along with the same size matches and no duplication. Further the other assemblage like the braincase along with articulated occipital condyle GSP/MSM-62-19 and postcranial materials were found within a 10 - 15 m estimated length oval trending northeast to southwest. The fossils field orientation tell the head orientation in 
the northeast end. The skull materials GSP/MSM-79-19 and GSP/MSM-80-19 were found on the base of $50 \mathrm{~m}$ slope, directly below the skeletal head site. In other words the braincase and postcranial materials found $50 \mathrm{~m}$ toward northwest (upward on slope) from the location of skull materials GSP/MSM-79-19 and GSP/MSM-80-19. So the cranial and postcranial materials seem to be associated as a single individual because found in the same locality and same formation along with the same size matches and no duplication. Fossils are housed in museum of Geological Survey of Pakistan, Quetta.

Referred specimens: Many referred skeletons and assemblages from Top Kinwa 16 at latitude $29^{\circ} 41^{\prime} 17^{\prime \prime} \mathrm{N}$ and longitude $69^{\circ} 24^{\prime} 00^{\prime \prime} \mathrm{E}$, Mari Bohri 15 locality at latitude $29^{\circ} 42^{\prime} 08^{\prime \prime} \mathrm{N}$; longitude $69^{\circ} 15^{\prime} 08^{\prime \prime} \mathrm{E}$, south Kinwa 4 s locality at latitude $29^{\circ} 41^{\prime} 00^{\prime \prime} \mathrm{N}$ and longitude $69^{\circ} 23^{\prime} 09^{\prime \prime} \mathrm{E}$, and mid Bor 2 locality at latitude $29^{\circ} 41^{\prime} 12.8^{\prime \prime} \mathrm{N}$, and longitude $69^{\circ} 23^{\prime} 07^{\prime \prime} \mathrm{E}$ of Pakistan and one skeleton from Chhota Simla locality of India were reported in [11].

Type locality, horizon and age: The holotype was discovered in an area designated as Alam 19 or central Alam 19c (latitude $29^{\circ} 41^{\prime} 0.7^{\prime \prime} \mathrm{N}$; longitude 69²3'58"E) (Figure 4), Barkhan district, Balochistan, Pakistan. Host horizon is Vitakri Formation (Figure 3) of Fort Munro Group [6]. Its age is the latest Maastrichtian [13]. The Vitakri Formation is terrestrial deposit [5] and well exposed in the Mari Bohri-Vitakri-Fort Munro areas and surroundings of eastern Balochistan and western part of South Punjab. The other terrestrial and significant exposures (for bones and egg collections because relatively close to Gujarat of India which yielded these fossils) are found as discontinuous exposures in the core of thrusted Laki anticline located in the easternmost part of Kirthar foldbelt like the Bara/Khadro and its southern continuation, Jamshoro district, Sindh, Pakistan.

Diagnosis: Gspsaurus pakistani sharing with Titanosauria as procoelous caudals (except first biconvex caudal), forward insertion of neural arches on caudals, prominent olecranon process on ulna and vertebrae lacking hyposphene-hypantrum articulations. Gspsaurus pakistani shares with Poripuchia on basis of procoelous distal and distalmost caudals. Gspsauridae and Gspsaurinae based on its type species G. pakistani. Gspsaurus pakistani characterised by V-shaped anterior dentary symphysis while Saraikimasoom vitakri has U-shaped anterior dentary symphysis, lense shaped (slightly more anteroposteriorly long than its transverse broad width) proximal tibia while Pakisaurus balochistani and Sulaimanisaurus gingerichi has transversely compressed flat proximal tibia and Saraikimasoom vitakri has square shaped (transverse and anteroposterior width are equal) proximal tibia; transversely long oval shaped (anteroposteriorly compressed) distal tibia while Pakisaurus balochistani and Sulaimanisaurus gingerichi has transversely broad distal tibia. Further comparison reported in pages 461-464 of [11].

Description: Gspsaurus pakistani skull was described and figured in the conference extended abstract 2014 [19], later on described and figured in 2015 [20], and the remaining associated materials cannot be included due to size limit of 
papers The recent updated descriptions and comparisons with holotypic cranial and postcranials were presented in pages $464-484$ of a single paper [11]. The Gspsaurus pakistani caudal vertebrae features do not match exactly with the holotypic caudal vertebrae of Marisaurus jeffi [21], so its referral was not justified and consequently new name Gspsaurus pakistani was established on diagnostic holotypic specimens [11] [19] [20]. However the reference [11] referred holotypic materials of Marisaurus jeffi to Gspsaurus pakistani only on overlapping caudals and a few limb elements (to reduce number of taxa) but some features of overlap materials do not support exactly. It is also necessary to mention that the paper on establishment of five sauropods (including Marisaurus jeffi) from Pakistan [22] was submitted in 2003 for Pakistan Geological Congress scheduled in 2003. Later on I submitted manuscript [23] to Journal of Himalayan Earth Sciences and this was published in 2003 [23]. Meanwhile the Pakistan Geological Congress was shifted from 2003 to April 2004, so the paper on five sauropods [22] appears later than the paper on partial cranial materials [23]. Here a few corrections are mention that the abbreviation $\mathrm{T}$ is mistyped as $\mathrm{P}$ in the second abbreviation of central column (upper), and $\mathrm{T}$ is mistyped as $\mathrm{Ph}$ the first abbreviation in the central column (lower) in Figure 1 of [11] regarding Gspsaurus skull. In actual these are teeth.

\subsubsection{Saraikimasoom vitakri Titanosaur from Pakistan}

\section{Systematic paleontology:}

Dinosauria [14];

Saurischia [15];

Sauropoda [16];

Titanosauriformes [17];

Titanosauria [18];

Poripuchia new clade;

Definition same as above;

Gspsauridae new family;

Definition same as above;

Saraikimasoominae new subfamily.

Definition: Saraikimasoom, Balochisaurus, Nicksaurus, their most recent common ancestor and all of its descendants.

Included species: Saraikimasoom vitakri, Balochisaurus malkani and Nicksaurus razashahi.

Diagnosis: Comparison and diagnosis of Saraikimasoominae and Gspsaurinae is mentioned as above.

1) Saraikimasoom new genus

Type and only known species: Saraikimasoom vitakri, new species;

Type locality, horizon and age: As for type and only species;

Diagnosis: See diagnosis for type and only species below;

Etymology: Saraiki, in honor of Saraiki people and language, masoom, Urdu and Saraiki language for innocent. Here the name Saraikimasoom used for the 
innocent (animal) of Saraiki area of Pakistan.

2) Saraikimasoom vitakri new species

(Figure 5)

Etymology: The species name vitakri honor the host Vitakri Formation and Vitakri area.

Holotype: An isolated snout GSP/MSM-142-4 bearing upper and lower jaws consisting of articulated left and right premaxillae, left and right maxillae, dorsal and ventral palatal process, left and right dentary and teeth (Figure 5). The holotype is also shown in Figure 1 and Figure 2 of [12]. This holotype is best preserved and also the one with the largest amount of diagnostic features. This holotype provides the complete teeth row. Different elements of snout along with mandibles with teeth are preserved as articulated which show it belongs to a single individual. Holotype is housed in the museum of Geological Survey of Pakistan, Quetta.

Type locality, horizon and age: The holotype was discovered in an area designated as south Kinwa 4 or 4 s (latitude $29^{\circ} 40^{\prime} 57^{\prime \prime N} \mathrm{~N}$; longitude $69^{\circ} 23^{\prime} 09^{\prime \prime} \mathrm{E}$ ) (Figure 4) of Vitakri area, Barkhan district, Balochistan Province, Pakistan. The host horizon is the Vitakri Formation (Figure 3) of Fort Munro Group [6]. Its age is the latest Maastrichtian [13].

Referred specimens: Referred assemblages from north Kinwa 4n (skeleton), Mari Bohri 15 and mid Sangiali 1 (latitude $29^{\circ} 41^{\prime} 53^{\prime \prime N}$; longitude 69 $23^{\prime} 56^{\prime \prime} \mathrm{E}$ ) and other localities were referred to Saraikimasoom vitakri [12]. Here a correction is mentioned that the Mari Bohri assemblage of Balochisaurus malkani was referred to Saraikimasoom vitakri (mistyped as Gspsaurus pakistani at the end of second paragraph of page 380 in [12]. These fossils are housed in the museum of Geological Survey of Pakistan, Quetta.

Diagnosis: Saraikimasoom vitakri sharing with Titanosauria as procoelous caudals (except first biconvex caudal), forward insertion of neural arches on caudals, prominent olecranon process on ulna and vertebrae lacking hyposphene-hypantrum articulations. Saraikimasoom vitakri shares with Poripuchia on the basis of procoelous distal and distalmost caudals. The sharing with Poripuchia and Gspsauridae is mentioned as above. Saraikimasoominae based on its type species. Saraikimasoom vitakri characterised by U-shaped anterior dentary symphysis while Gspsaurus pakistani has V-shaped anterior dentary symphysis; square shaped (transverse and anteroposterior width are equal) proximal tibia while Gspsaurus pakistani has lense shaped (slightly more anteroposteriorly long than its transverse broad width) proximal tibia and Pakisaurus balochistani and Sulaimanisaurus gingerichi has transversely compressed flat proximal tibia. Further diagnosis and comparison can be seen in pages 381-383 of [12].

Description: Saraikimasoom vitakri was first reported, described and figured in the conference extended abstract 2014 [19] and later described and figured in 2015 [20] which was based on holotypic isolated snout GSP/MSM-142-4 found from south Kinwa locality 4 or 4s (Figure 4) of Vitakri area, Barkhan district, 
Balochistan Province, Pakistan. The recent updated description and comparisons were presented in pages 383-402 of [12].

\subsubsection{Pakisaurus balochistani Titanosaur from Pakistan}

Systematic paleontology:

Dinosauria [14];

Saurischia [15];

Sauropoda [16];

Titanosauriformes [17];

Titanosauria [18];

Poripuchia new clade;

See definition above;

Pakisauridae new family.

Definition: Pakisaurus, Isisaurus, Sulaimanisaurus, Khetranisaurus, their most recent common ancestor and all of its descendants.

Included species: Pakisaurus balochistani, Isisaurus colberti, Sulaimanisaurus gingerichi and Khetranisaurus barkhani.

Diagnosis: The diagnosis and comparison of Pakisauridae and Gspsauridae are given above. Pakisauridae features based on type genus and species P. balochistani.

1) Pakisaurus new genus

Type and only known species: Pakisaurus balochistani, new species.

Type locality, horizon and age: As for type and only species.

Diagnosis: See diagnosis for type and only species below.

Etymology: Paki, in honor of the host country Pakistan, saurus, Greek for lizard.

2) Pakisaurus balochistani new species

(Figure 7)

Etymology: The species name balochistani in honor of Baloch tribe.

Holotype: Presacral vertebrae GSP/MSM-340-4, GSP/MSM-341-4, GSP/MSM342-4, GSP/MSM-376-4, GSP/MSM-517-4, GSP/MSM-800-4, GSP/MSM-809-4, GSP/MSM-810-4 and GSP/MSM-1011-4; cervicodorsal vertebra GSP/MSM-133-4; sacral pair GSP/MSM-1008-4; caudal vertebrae GSP/MSM-11-4, GSP/MSM-12-4, GSP/MSM-13-4, GSP/MSM-14-4, GSP/MSM-207-4, GSP/MSM-763-4 and GSP/ MSM-1010-4; neural spine GSP/MSM-601-4; neural arches parts GSP/MSM878-4, GSP/MSM-804-4 and GSP/MSM-805-4; diapophysis/prezygapophysis GSP/ MSM-878a-4; proximal scapula in two pieces GSP/MSM-318-4 and GSP/MSM319-4; proximal scapula GSP/MSM-201-4; mid scapula GSP/MSM-590-4; mid scapula sections GSP/MSM-593-4; left mid scapula GSP/MSM-203-4; right distal scapula with glenoid surface GSP/MSM-205-4; left distal scapula with glenoid surface GSP/MSM-162-4; anterolateral sternal GSP/MSM-355-4 and sternal medial convex GSP/MSM-598-4; proximal right humerus GSP/MSM-202-4; humerus parts GSP/MSM-268-4, GSP/MSM-210-4 and GSP/MSM-210a-4; distal humerus 
GSP/MSM-193-4 (reverse view than proximal); distal radius GSP/MSM-159-4; a pair of proximal ulnae-left and right proximal ulnae GSP/MSM-603-4 and GSP/ MSM-600-4, rays of proximal ulna GSP/MSM-211-4 and GSP/MSM-678-4; partial metacarpals GSP/MSM-280-4 and GSP/MSM-970-4; proximal anterior process of ilium GSP/MSM-971-4 and GSP/MSM-972-4 two piece; part of Ilium? GSP/MSM594-4; posterior part of ilium with rod type rib like process GSP/MSM-806-4; right proximal femur GSP/MSM-595-4 and distal right femur GSP/MSM-200-4; proximal right fibula GSP/MSM-349-4; distal fibula GSP/MSM-580-4; proximal left fibula GSP/MSM-384-4; and partial metatarsal GSP/MSM-350-4 (Figure 7). It can be seen in Figures 1-3 of [13]. These materials are found on 2 sites which are about $50 \mathrm{~m}$ apart trending north south as shown black circles on map (Figure 4). The holotypic fossils are found as surface finds in the same formation, same locality, no duplication and fit size show associated bones of a single individual. All these collections are housed in the museum of Geological Survey of Pakistan, Quetta.

Type locality, horizon and age: The holotype was discovered as two assemblages in south Kinwa 4 locality at latitude $29^{\circ} 41^{\prime} 05^{\prime \prime} \mathrm{N}$ and longitude $69^{\circ} 23^{\prime} 05^{\prime \prime} \mathrm{E}$ (south of foot track including vertebrae and other bones), and at latitude $29^{\circ} 41^{\prime} 06^{\prime \prime} \mathrm{N}$ and longitude $69^{\circ} 23^{\prime} 05^{\prime \prime} \mathrm{E}$ (north of foot track including complete diagnostic humerus and other bones) (Figure 4), Barkhan district, Balochistan. The host horizon is the Vitakri Formation (Figure 3) of Fort Munro Group [6]. Its age is the latest Maastrichtian [13].

Referred specimens: Many fossils are referred [13], among these the most significant is the associated assemblage from lower Bor 2 (latitude $29^{\circ} 41^{\prime} 12^{\prime \prime} \mathrm{N}$; longitude $69^{\circ} 22^{\prime} 37^{\prime \prime E}$ ) (shown in Figure 4 of [13]) including dentary ramus GSP/ MSM-143-2 (Figure 7) [7], and north Alam 19n (latitude 29 $41^{\prime} 15^{\prime \prime N}$; longitude $69^{\circ} 24^{\prime} 01^{\prime \prime E}$ ) (shown in Figure 4 of [13]) localities from Pakistan and some fossils from different localities of India [13]. Referred fossils from Pakistan are housed in the museum of Geological survey of Pakistan, Quetta. The femur, humerus and caudal vertebra of lower Bor skeleton overlapped with the Pakisaurus balochistani holotypic femur, humerus and caudals [13]. The lower Bor diagnostic humerus GSP/ MSM-180-2 (shown in Figure 4 of [13]) represents expanded radial condyle which matches with Pakisaurus balochistani holotypic humerus GSP/MSM-193-4 (shown in Figure 1 of [13]), while differentiated from Sulaimanisaurus gingerichi which have no expanded radial condyles. Further the lower Bor caudal vertebra GSP/MSM-16-2 is tall with ratio 1 of mid transverse dorsal width to the mid ventral width which is again differentiated from Sulaimanisaurus gingerichi (squarish caudals), Gspsaurus pakistani (ventral reduction with ratio 1.5) and Saraikimasoom vitakri (ventral compression with ratio about 2). Conclusively the proximal slender flat tibia GSP/MSM-72-2 and anteroposteriorly broad distal tibia GSP/MSM-186-2 of lower Bor skeleton provide additional informations of Pakisaurus balochistani and also differentiate from Sulaimanisaurus gingerichi, Gspsaurus pakistani and Saraikimasoom vitakri (for detail tibial discussion see in [13]). 


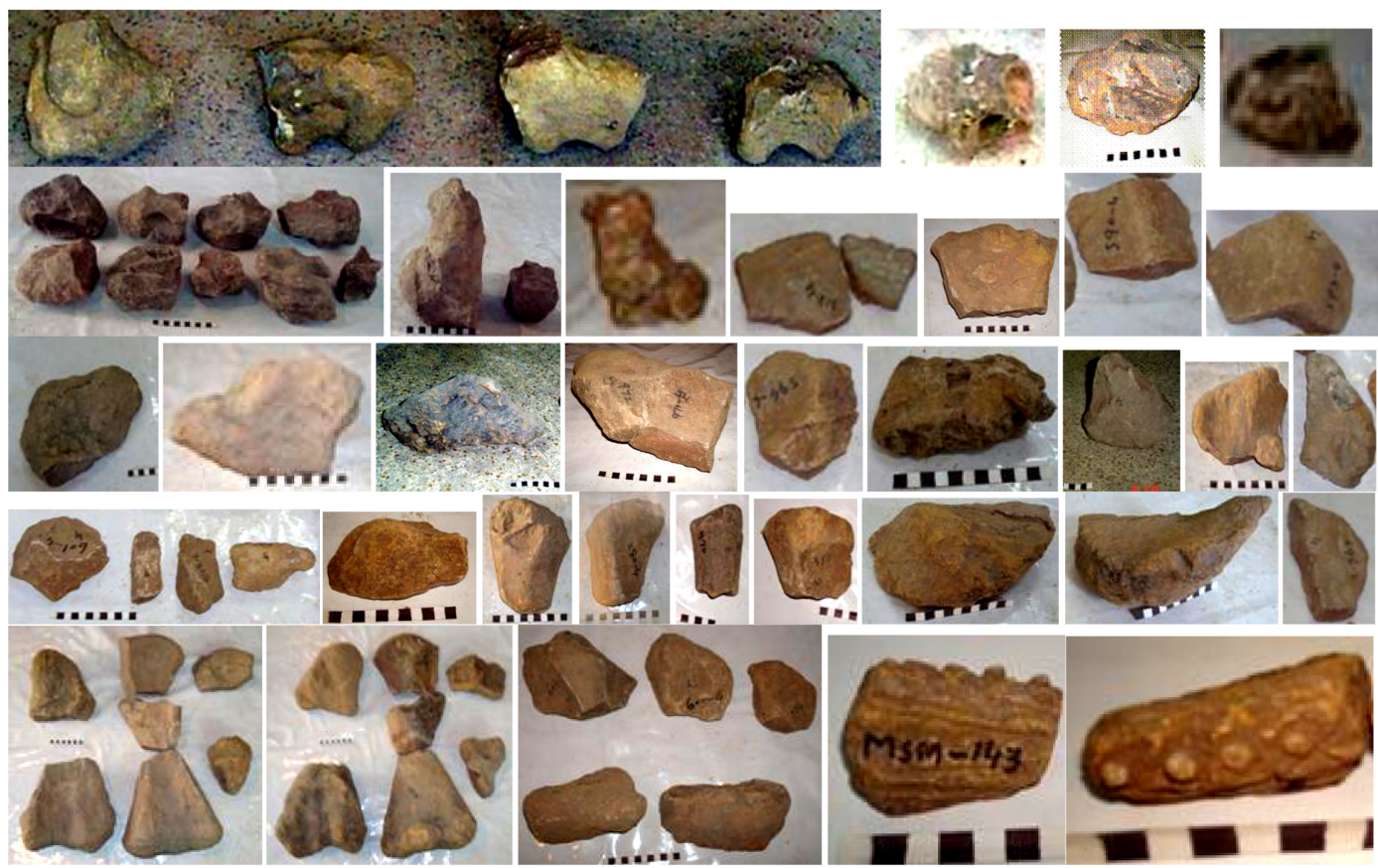

Figure 7. Pakisaurus balochistani holotypic fossils shown in rows 1, 2, 3, 4 and 5 (except the last two photos in row 5 which are referred) collected from south Kinwa 4 locality (Figure 4), Barkhan district, Balochistan province, Pakistan. Row 1, caudal vertebrae GSP/MSM-11-4, GSP/MSM-12-4, GSP/MSM-13-4 and GSP/MSM-14-4; cervicodorsal vertebra GSP/MSM-133-4; presacral vertebra GSP/MSM-1011-4; sacral pair GSP/MSM-1008-4. Row 2, p1, subrow 1, presacral vertebrae GSP/MSM-340-4, GSP/MSM-809-4, GSP/ MSM-1011-4, GSP/MSM-517-4; subrow 2, presacral vertebrae GSP/MSM-810-4, GSP/MSM-342-4, GSP/ MSM-800-4, GSP/MSM-341-4, GSP/MSM-376-4; p2, anterior and mid caudal vertebrae GSP/MSM-207-4 and GSP/MSM-763-4; p3, mid caudal vertebra GSP/MSM-1010-4; p4, proximal scapula in 2 pieces GSP/ MSM-318-4, GSP/MSM-319-4; p5, proximal scapula GSP/MSM-201-4; p6, mid scapula GSP/MSM-590-4; p7, mid scapula sections GSP/MSM-593-4. Row 3, left mid scapula GSP/MSM-203-4, right distal scapula with glenoid surface GSP/MSM-205-4; left distal scapula with glenoid surface GSP/MSM-162-4; proximal anterior process of ilium GSP/MSM-971-4 and GSP/MSM-972-4; part of Ilium? GSP/MSM-594-4; posterior part of ilium with rib type process GSP/MSM-806-4; distal radius GSP/MSM-159-4; proximal fibula GSP/MSM-349-4; distal fibula GSP/MSM-580-4. Row 4, p1, neural spine GSP/MSM-601-4, neural arches parts GSP/MSM-878-4, GSP/MSM-804-4 and GSP/MSM-805-4; p2, diapophysis/postzygapophysis GSP/MSM-878a-4; p3,4, partial metacarpal GSP/MSM-280-4 in 2 views; p5,6, partial metacarpals GSP/ MSM-970-4, GSP/MSM-350-4; p7,8, anterolateral sternal GSP/MSM-355-4 in 2 views; p9, sternal medial convex GSP/MSM-598-4. Row 5, p1,2, column 1, proximal and distal right femur GSP/MSM-595-4 and GSP/MSM-200-4; column 2, proximal humerus GSP/MSM-202-4, mid humerus GSP/MSM-268-4, distal humerus GSP/MSM-193-4 (reverse view than proximal); column 3, mid humerus cross sections GSP/ MSM-210-4, GSP/MSM-210a-4. P3, subrow 1, left and right proximal ulnae GSP/MSM-603-4 and GSP/ MSM-600-4, proximal left fibula GSP/MSM-384-4; subrow 2, rays of proximal ulna GSP/MSM-211-4 and GSP/MSM-678-4. P4,5, Referred dentary ramus with articulated teeth GSP/MSM-143-2 in 2 views found from Bor 2 locality, Barkhan district, Balochistan. Scale, each black or white digit is $1 \mathrm{~cm}$, for others scale see [7] [13] [21].

Diagnosis: Pakisaurus balochistani shares with the Titanosauria as procoelous caudals, forward insertion of neural arches on caudals, vertebrae lacking hyposphene-hypantrum articulations, prominent olecranon process on ulna and neural spine single and not bifid. Pakisaurus balochistani shares with Poripuchia as procoelous anterior, middle, posterior and posteriormost caudal vertebrae except first 
biconvex in some taxa (because in Poripuchia anterior, middle and distal caudals found are all procoelous, while in lithostrotian distal caudals are not procoelous). Pakisauridae features based on type species Pakisaurus balochistani. The combined features are autapomorphies of Pakisaurus balochistani like the tall caudal centra without ventral reduction, anteriorly expanded radial condyle of distal femur while Sulaimanisaurus gingerichi and Isisaurus colberti has distal humerus without expanded radial condyle, the transversely compressed flat tibia while Saraikimasoom vitakri has square shaped (transverse and anteroposterior width are equal) proximal tibia and Gspsaurus pakistani has lense shaped (slightly more anteroposteriorly long than its transverse broad width) proximal tibia; Pakisaurus balochistani has transversely compressed flat proximal tibia like Sulaimanisaurus gingerichi but Pakisaurus balochistani has more transversely broad distal tibia than Sulaimanisaurus gingerichi. Further diagnosis and comparisons can be seen in pages 418-420 of [13].

Description: Pakisaurus balochistani was first reported and described in conference 2004 [22] and later on described and figured in 2006 [21]. The recent updated description and comparisons of cranial and postcranial fossils was presented in pages $420-431$ of [13]. The dentary ramus GSP/MSM-143-2 collected from Bor locality may be associated with postcrania of Pakisaurus from this locality represents dentary ramus with teeth as shown in Figure 2(a) of [10]. This ramus bears circular to subcircular and spaced teeth. Teeth size varies from 5.5 $\mathrm{mm}$ to $7 \mathrm{~mm}$. Its large 3 teeth are $7 \mathrm{~mm}$ long and $5.5 \mathrm{~mm}$ wide while fourth tooth is relatively small (Figure 7). The teeth are not connected with each other but spaced varying from $6 \mathrm{~mm}$ to $8 \mathrm{~mm}$ shows Pakisaurus has slender and spaced teeth. The preserved crowns of Pakisaurus show same thickness while Saraikimasoom and Gspsaurus have conical tapering teeth. Jaw ramus clearly show parallel and alternated fine ridges and grooves, longitudinally trending anteroposteriorly throughout all preserved.

\subsubsection{Sulaimanisaurus gingerichi Titanosaur from Pakistan Systematic paleontology: \\ Dinosauria [14]; \\ Saurischia [15]; \\ Sauropoda [16]; \\ Titanosauriformes [17]; \\ Titanosauria [18]; \\ Poripuchia new clade; \\ Definition same as above; \\ Pakisauridae new family; \\ See as above; \\ Sulaimanisaurus gingerichi new genus and new species.}

(Figure 5)

Etymology: Sulaimani, in honor of the host Sulaiman basin, saurus, Greek lizard. Species name gingerichi, in honor of Prof. Dr. Philip D. Gingerich, Univer- 
sity of Michigan, USA who arranged to verify the first dinosaur bones from $\mathrm{Pa}$ kistan.

Holotype: Caudal vertebrae GSP/MSM-17(a)-4, GSP/MSM-18-4, GSP/MSM19-4, GSP/MSM-20-4, GSP/MSM-21-4, GSP/MSM-21(a)-4 and GSP/MSM-22-4 (Figure 5). These fossils were shown in Figures 5-8 of [21]. These fossils are housed in the museum of Geological Survey of Pakistan, Quetta. The holotypic fossils are found at the same time as surface finds in the same formation, same site, no duplication and fit size show associated bones of a single individual.

Type locality, horizon and age: The holotype was discovered in an area designated as south Kinwa 4 type locality (latitude $29^{\circ} 40^{\prime} 54^{\prime \prime} \mathrm{N}$; longitude $69^{\circ} 23^{\prime} 04^{\prime \prime} \mathrm{E}$ ) (Figure 4), Barkhan district, Balochistan. The host horizon is the Vitakri Formation (Figure 3) of Fort Munro Group [6]. Its age is the latest Maastrichtian [13].

Referred specimens: The referred fossils are associated flattened tibia GSP/ MSM-235-7, fibula GSP/MSM-253-7 and metatarsal GSP/MSM-296-7 found from Zubra peak 7 (latitude $29^{\circ} 43^{\prime} 12^{\prime \prime N} \mathrm{~N}$ longitude $69^{\circ} 30^{\prime} 16^{\prime \prime} \mathrm{E}$ ) of Dhaola-Gambrak area (Figure 5), (shown in Figure 6 of [13]); associated distal humerus GSP/ MSM-262-1 and distal femur GSP/MSM-232-1 found from lower Sangiali 1 (latitude $29^{\circ} 41^{\prime} 55^{\prime \prime N}$; longitude $69^{\circ} 23^{\prime} 54^{\prime \prime E}$ ) (Figure 5) (shown in Figure 6 of [13]); fragmentary caudal vertebra GSP/MSM-23-3 from Shalghara 3, and three fragmentary but seem associated caudal vertebrae GSP/MSM-24-15, GSP/MSM-2515 and GSP/MSM-26-15 from Mari Bohri 15 (shown in Figures 5-8 of [21]), Barkhan district, Balochistan, Pakistan.

Diagnosis: The Sulaimanisaurus gingerichi share with Titanosauria as procoelous caudals, forward insertion of neural arches on caudals, and caudal vertebrae lacking hyposphene-hypantrum articulations and neural spine seems to be single and not bifid. It shares with Poripuchia on basis of procoelous distal and distalmost caudals. The Sulaimanisaurus gingerichi shares with Pakisauridae the ratio of mid transverse width above and below of mid caudal centrum is about 1.00 and slender flattened tibia with anteroposteriorly broad distal ends. Sulaimanisaurus gingerichi has square shaped caudals; flattened tibia with relatively less anteroposteriorly broad distal tibia than Pakisaurus, while Gspsaurus and Saraikimasoom have transversely broad; and humerus without expanded radial condyle while Pakisaurus, Gspsaurus and Saraikimasoom have expanded radial condyle.

Description: Its caudal vertebrae were described in conference 2004 [22] and in 2006 in pages 112 and 113 of [21]. It's referred limb elements like tibia, femur, humerus and others are described in pages 431, 432 and 433 of [13]. The species name gingerichi was mistyped as gingrechi in [22]. The correct is gingerichi.

\subsubsection{Khetranisaurus barkhani Titanosaur from Pakistan Systematic paleontology: \\ Dinosauria [14]; \\ Saurischia [15]; \\ Sauropoda [16];}


Titanosauriformes [17];

Titanosauria [18];

Poripuchia new clade;

Definition same as above;

Pakisauridae new family;

For definition see above;

Khetranisaurus barkhani new genus and new species.

(Figure 5)

Etymology: Khetrani, in honor of host Khetran tribe, saurus, Greek for lizard. The species name barkhani honors the host Barkhan district of Balochistan.

Holotype: Caudal vertebrae GSP/MSM-27-4 and GSP/MSM-28-4 (Figure 5) housed in the museum of Geological Survey of Pakistan, Quetta. It was shown in Figures 5-8 of [21]. The caudal vertebrae found at the same time from same locality, matching features, fit size and no duplication show a single individual.

Type locality, horizon and age: The holotype was discovered in an area designated as mid Kinwa locality 4 or $4 \mathrm{~m}$ (latitude $29^{\circ} 41^{\prime} 04^{\prime \prime} \mathrm{N}$; longitude $69^{\circ} 23^{\prime} 17^{\prime \prime} \mathrm{E}$ ) (Figure 4) of Vitakri area, Barkhan district, Balochistan Province, Pakistan. The number after the locality name is locality number. The host formation is the Vitakri Formation (Figure 3) of Fort Munro Group [6]. Its age is the latest Maastrichtian [13].

Referred specimen: On later visit the caudal vertebra matching with holotypic vertebra and some limb bones were observed in the mid Kinwa 4 m (Figure 4) type locality [19].

Diagnosis: Khetranisaurus barkhani share with Titanosauria as procoelous caudals, forward insertion of neural arches on caudals, and caudal vertebrae lacking hyposphene-hypantrum articulations and neural spine seems to be single and not bifid. Khetranisaurus barkhani shares with Pakisauridae on the basis of ratio of transverse dorsal width to the transverse ventral width which is close to 1 (slightly less than 1). Pakisauridae are defined as above. Khetranisaurus barkhani uniqueness among Indo-Pakistani titanosaurs is the width of dorsal view of caudal vertebrae which is less than the width of ventral view of caudal vertebrae, while in Pakisaurus balochistani and Isisaurus colberti its dorsal and ventral widths are about equal, while in Gspsaurus pakistani its dorsal width is more than its ventral width (ventral width is reduced) and in Saraikimasoom vitakri its dorsal width is significantly more than its ventral width (ventral width is significantly reduced). Further Khetranisaurus barkhani have a ventral groove of elongated oval/hexagonal shape bounded by wall between the chevron facets depressions, while other Indo-Pakistani titanosaur taxa are represented by large open groove. Khetranisaurus barkhani have a small resistant tubera on the ventral margin of anterior articular rim of caudal just on the front of oval groove, while other Indo-Pakistani titanosaur taxa bear no such tubera. Further lateral surfaces on ventral view cannot be seen and on dorsal view can be seen in caudals of Khetranisaurus barkhani, while lateral surfaces on ventral view clearly ob- 
served and on dorsal view cannot be seen in caudals of Gspsaurus pakistani and Saraikimasoom vitakri, lateral surfaces on dorsal view cannot be seen in caudals of Pakisaurus balochistani and Isisaurus colberti. Khetranisaurus barkhani have more transversely broad or transversely elongated oval shape or strongly dorsoventrally compressed neural canal, while other Indo-Pakistani titanosaur taxa like Gspsaurus pakistani, Saraikimasoom vitakri, Pakisaurus balochistani and Isisaurus colberti all show circular neural canal and do not show no such strong broadness.

Description: Khetranisaurus barkhani was first reported and described in conference 2004 [22] and later on described and figured in 2006 which can be seen in page 113 of [21].

\subsection{Theropods from the Latest Maastrichtian of Pakistan}

Two theropods are reported from Pakistan so far.

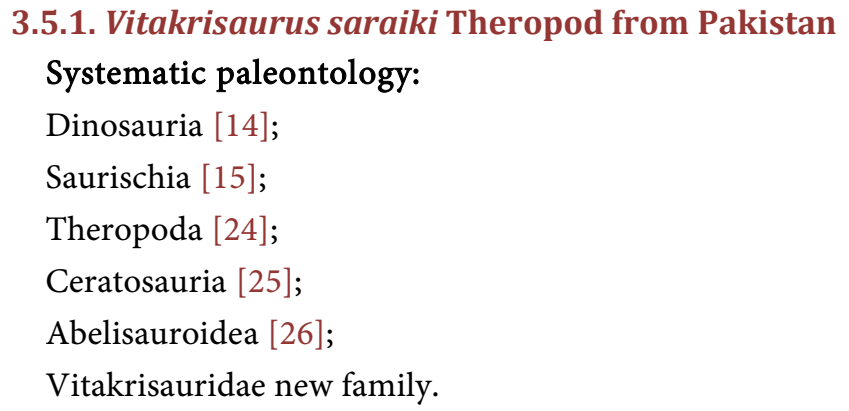

Definition: Vitakrisaurus, Vitakridrinda, Rajasaurus, Rahiolisaurus, their most recent common ancestor and all of its descendants.

Included species: Vitakrisaurus saraiki, Vitakridrinda sulaimani, Rajasaurus narmadensis and Rahiolisaurus gujaratensis.

Diagnosis: Features same as for type species.

Vitakrisaurus saraiki new genus and new species.

(Figure 8)

Etymology: Vitakri, in honor of host Vitakri Formation and locality, saurus, Greek lizard. The species name saraiki, in honor of Saraiki language and Saraiki people and Saraiki Wasabi-the living of Saraiki peoples called Saraikistan.

Holotype: Right hand/manus GSP/MSM-303-2; proximal ulna GSP/MSM-1076-2 cross section; partial vertebra GSP/MSM-780-2; humerus cross sections GSP/MSM1044-2, GSP/MSM-984-2 and GSP/MSM-1027-2; one anterior caudal GSP/MSM53-2 and two mid-caudal vertebrae GSP/MSM-54-2 and GSP/MSM-55-2 (Figure 8). The holotypic fossils are found as surface finds in the same formation, same locality, no duplication and fit size show associated bones of a single individual. All these fossils are hosted in the museum of Geological Survey of Pakistan, Quetta.

Referred specimens: Anterior dentary GSP/MSM-140-3, dentary ramus with articulated teeth GSP/MSM-5-3 and Dorsal vertebra GSP/MSM-57-3 from Shalghara 3 of Vitakri area; proximal femur GSP/MSM-1049-K, mid cross section of 


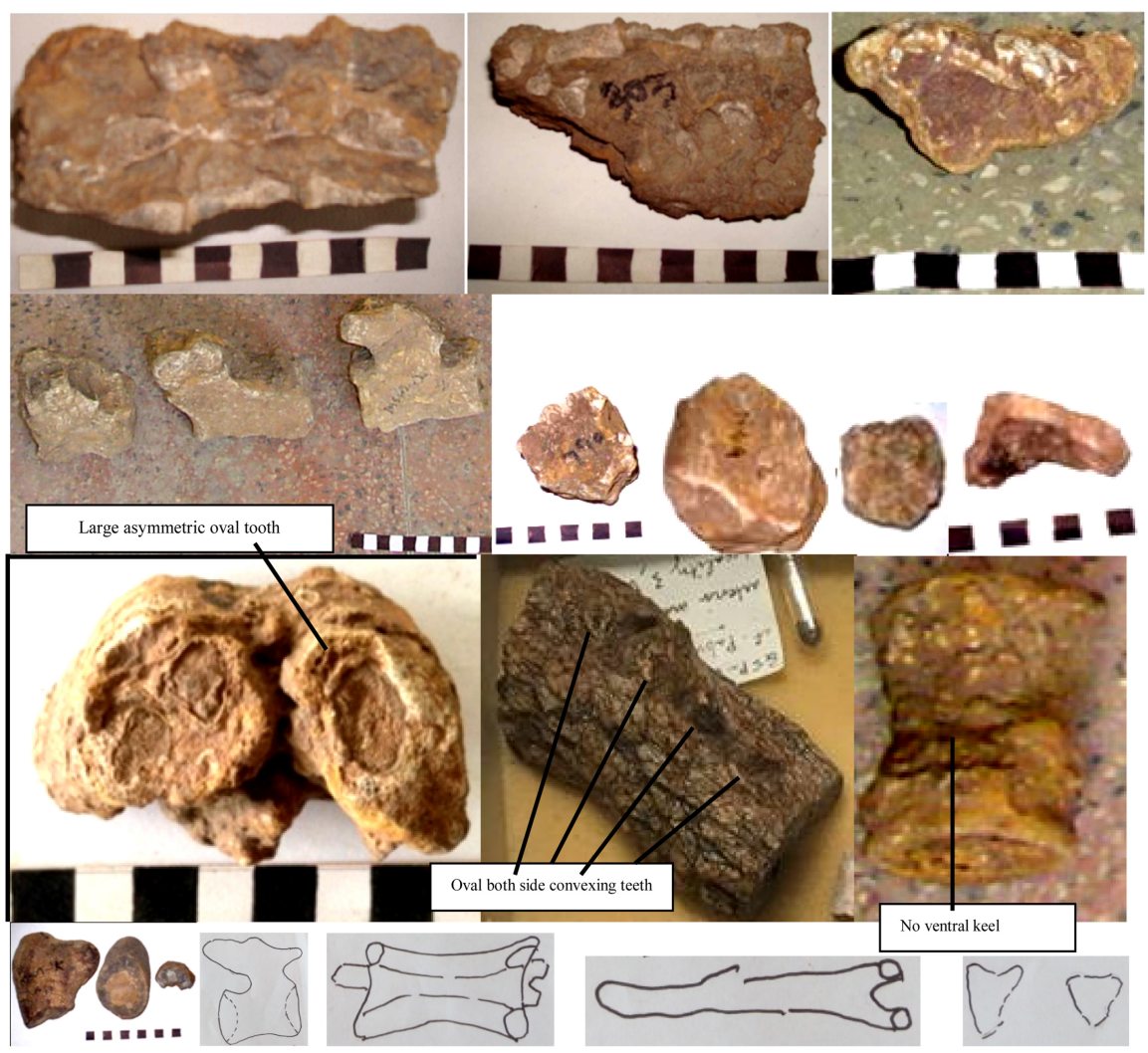

Figure 8. Vitakrisaurus saraiki holotypic fossils (row 1 and 2) collected from mid Bor 2 locality (Figure 4), Barkhan district, Balochistan, and referred fossils (row 3 and 4). Row 1, right hand/manus GSP/MSM-303-2 in dorsal and medial views; proximal ulna GSP/ MSM-1076-2 cross sectional view. Row 2, one anterior caudal GSP/MSM-53-2 and two mid-caudal vertebrae GSP/MSM-54-2 and GSP/MSM-55-2 in lateral view; partial vertebra GSP/MSM-780-2; humerus cross sectional bones GSP/MSM-1044-2, GSP/MSM-984-2 and GSP/MSM-1027-2. Row 3, Referred anterior dentary GSP/MSM-140-3, dentary ramus with four/five teeth GSP/MSM-5-3 and dorsal vertebra GSP/MSM-57-3 found from Shalghara 3 locality (Figure 4), Barkhan district, Balochistan. Row 4, p1, proximal femur GSP/MSM1049-K, mid cross section of femur GSP/MSM-1055-K, and peripheral bone of leg section GSP/MSM-1059-K from Karkh locality (for location of Karkh see in [10]), Khuzdar district, Balochistan, Pakistan. P2,3, Line drawings of tall amphicoelous caudal vertebra $\mathrm{K}$ 20/316 in right lateral and ventral views; 4 , its neural arch including prezygapophysis and postzygapophysis processes in dorsal view, and p5, two small chevrons K 20/318 [27] from Bara Simla hill, Jubbulpore, India. Scale, every black or white digit is $1 \mathrm{~cm}$.

femur GSP/MSM-1055-K and part of peripheral bone of leg section GSP/MSM1059-K from Karkh locality, Khuzdar district, Balochistan, Pakistan (Figure 8). Tall amphicoelous caudal vertebra K 20/316 and small chevrons K 20/318 (Figure 8) from India [27] were referred [28].

Type locality, horizon and age: The holotype was discovered in an area designated as mid Bor 2 (Figure 4) of Vitakri area, Barkhan district, Balochistan. The host horizon is the Vitakri Formation (Figure 3) of Fort Munro Group [6]. Its age is the latest Maastrichtian [13]. The grid reference of the mid Bor 2 type locality are latitude $29^{\circ} 41^{\prime} 12.8^{\prime \prime} \mathrm{N}$, and longitude $69^{\circ} 23^{\prime} 07^{\prime \prime} \mathrm{E}$.

Diagnosis and comparison: Vitakrisaurus saraiki overlapping features with 
Abelisauroidea Ceratosauria are as broad, small and low crown teeth, large hollow cavity enveloped by thick peripheral limb bones and medium to large sized amphicoelous vertebrae. Vitakrisaurus saraiki characters and comparison is as below. Dentary symphysis (GSP/MSM-140-3) shows weak anterior articulation and pitted structures. Vitakrisaurus form V-shaped anteriormost end of dentary symphysis (blunted as w-shaped) while Rahiolisaurus anterior jaw ramus shows curvature representing U-shaped anterior symphysis. Articulated first dentary tooth is large and biconvex (convexing on labial and also lingual sides) on one ramus, while $1^{\text {st }}$ and 2 nd dentary relatively small teeth on opposite relevant position on another ramus. This shows variation of teeth size on same position of both jaws/rami confirms assignment to theropods than mesoeucrocodile. Because mesoeucrocodile have mostly same size teeth on relevant position on both sides of rami/jaws like Mithasaraikistan and Pabwehshi. Dentary ramus (GSP/MSM-5-3) is thick and deep and represents rough pitted structures and irregular lineations. The teeth articulated with dentary ramus are relatively large to moderate in size, asymmetric oval and D-shaped and not closely contacted (Figure 8). The teeth are asymmetric D-shaped, oval and subcircular cross sectional shape and possibly low crown (interpreted from sharp decreasing of thickness) recurved teeth. Teeth have different morphology may belong to different positions. Vitakrisaurus has oval and biconvex teeth (convexing on labial and also lingual sides) while Vitakridrinda has commonly D-shaped, oval and subcircular teeth. Vitakrisaurus has spaced teeth while Indosuchus have short, recurved and closely contacted teeth. Vitakrisaurus anteroposteriorly broad teeth matching with Indosuchus but differ on teeth shape. Vitakrisaurus has oval shaped teeth while Vitakridrinda has D-shaped, oval and subcircular teeth and Rahiolisaurus has symmetrical cross sectional shape of teeth. Dentary ramus lack vertical ridges and also dental foramina. Vitakrisaurus teeth size and interdental spacing is almost same as Rahiolisaurus. Vitakrisaurus has relatively rounded mesial keel and sharp distal keel on one tooth while Rahiolisaurus has a faint mesial keel but rounded distal edge. Symmetric and asymmetric both type of teeth found in Vitakrisaurus, while Rahiolisaurus has symmetrical oval teeth (Rajasaurus has no preserved teeth for comparison). The anteroposterior width of teeth of Vitakrisaurus is same as Vitakridrinda teeth but relatively large than Rahiolisaurus teeth representing Vitakrisaurus and Vitakridrinda relatively larger animal than Rahiolisaurus. The postcranial diagnostic features and comparisons were presented in pages 523-528 of [28].

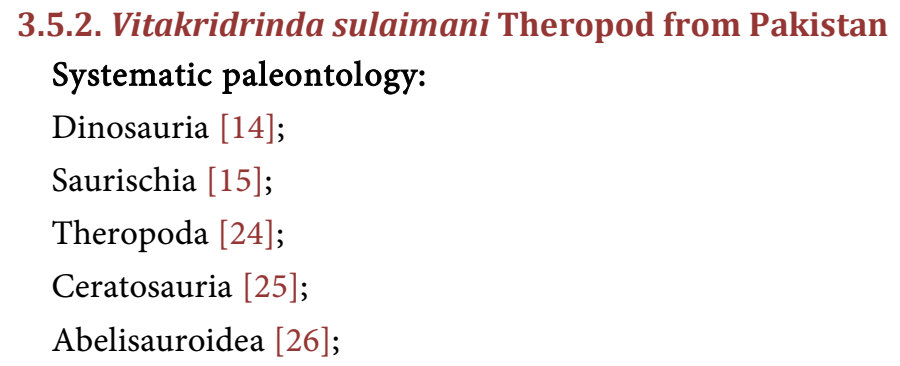


Vitakrisauridae new family.

Vitakridrinda sulaimani shares with Vitakrisauridae as dorsal centrum with parapophysis on the upper part of anterior caudal centra and forwardly inserted anteriorly neural arch on the dorsal aspect of centra. Definition is same as above.

Vitakridrinda sulaimani new genus and new species.

(Figure 9)

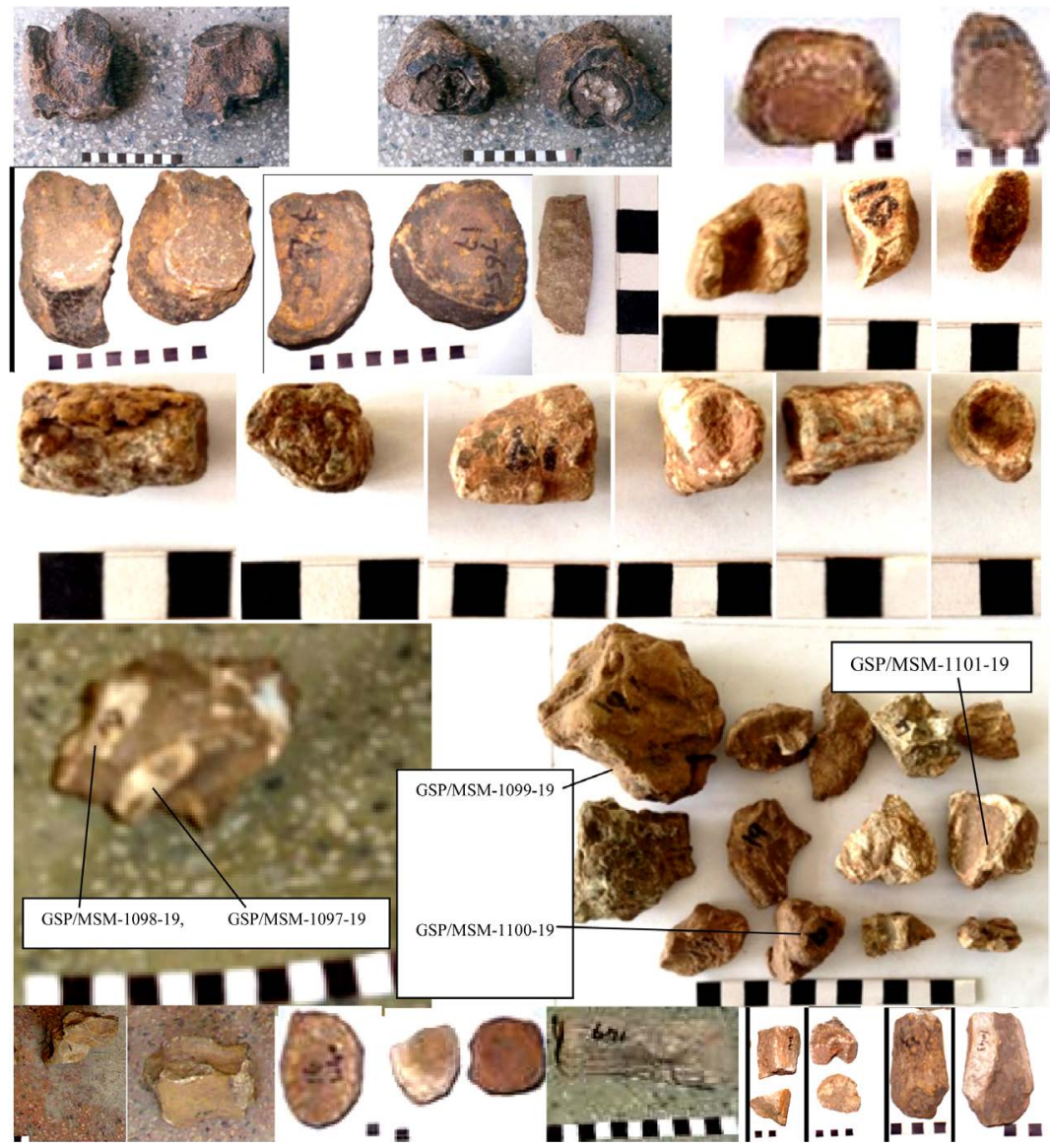

Figure 9. Vitakridrinda sulaimani holotypic bones (Row 1, 2, 3, 4) found from Alam 19 locality (Figure 4), Barkhan district, Balochistan, and referred fossils (row 5). Row 1, left and right femora GSP/MSM-59-19 and GSP/MSM-60-19 in 2 views; distal femur cross section GSP/MSM-1039-19 in 2 views. Row 2, tall dorsal centra GSP/MSM-706-19 and GSP/MSM-765-19 in 2 views; tooth GSP/MSM-1085-19; tooth cross section GSP/MSM1093-19; tooth cross section GSP/MSM-1090-19 in 2 views. Row 3, teeth GSP/MSM1089-19, GSP/MSM-1091-19 and GSP/MSM-1092-19 in 2 views. Row 4, p1, two teeth GSP/MSM-1097-19 and GSP/MSM-1098-19 as labeled; p2, three labeled teeth GSP/MSM1099-19, GSP/MSM-1100-19 and GSP/MSM-1101-19 (along with many cranial fragments). Row 5, anterior dorsal vertebra GSP/MSM-56-1 from Sangiali 1 area (Figure 4), anterior caudal vertebra GSP/MSM-58-15 from Mari Bohri 15 area (Figure 4); tall dorsal vertebra GSP/MSM-1040-16 and GSP/MSM-1048-16 from Top Kinwa 16 area (Figure 4); squarish mid caudal centrum GSP/MSM-282-15 from Mari Bohri 15 area (Figure 4); p3, distal caudal vertebra GSP/MSM-149-16 of whiplash tail, and metatarsals II/teeth (GSP/ MSM-1041-16 upper; GSP/MSM-1042-16 lower) in 2 views from Top Kinwa 16 area (Figure 4); metatarsal III or tooth (GSP/MSM-1043-4) in 2 views from south Kinwa 4 area (Figure 4). Scale, every black or white digit is $1 \mathrm{~cm}$. 
Etymology: Vitakri, in honor of host Vitakri Formation and locality, drinda, Urdu and Saraiki language meaning beast. The species name Vitakridrinda sulaimani based on the host Sulaiman basin and Koh Sulaiman mountain range.

Holotype: Teeth GSP/MSM-1085-19, GSP/MSM-1089-19, GSP/MSM-1091-19, GSP/MSM-1092-19, GSP/MSM-1097-19, GSP/MSM-1098-19, GSP/MSM-109919 GSP/MSM-1100-19 and GSP/MSM-1101-19; Teeth cross sections GSP/MSM1093-19 and GSP/MSM-1090-19; tall dorsal centra GSP/MSM-706-19 and GSP/ MSM-765-19; left and right femora GSP/MSM-59-19 and GSP/MSM-60-19; distal femur cross section GSP/MSM-1039-19 (Figure 9). A pair of femora found about $100 \mathrm{~m}$ (estimated) from the south of teeth material site. Teeth materials were found just close to snout/skull of Gspsaurus and rostrum of Induszalim, but also different than these genera. Fossils are housed in the museum of Geological Survey of Pakistan, Quetta. The holotypic fossils are found as surface finds in the same formation, same locality, no duplication and fit size show associated bones of an individual.

Referred specimens: Vitakridrinda sulaimani referred fossils include tall anterior dorsal vertebra GSP/MSM-56-1, GSP/MSM-1040-16 and GSP/MSM-104816; anterior caudal vertebra GSP/MSM-58-15, mid caudal vertebra GSP/MSM282-15; distal caudal vertebra GSP/MSM-149-16 of whiplash tail; teeth/metatarsals cross section II GSP/MSM-1041-16, GSP/MSM-1042-16; metatarsal III or tooth (GSP/MSM-1043-4) (Figure 9). In these metatarsals (teeth) specimens the number 10 was missed in Figure 3 of [28].

Type locality, horizon and age: The holotypic postcranial fossils were found at latitude $29^{\circ} 41^{\prime} 00^{\prime \prime} \mathrm{N}$, and longitude $69^{\circ} 23^{\prime} 58^{\prime \prime} \mathrm{E}$, and holotypic cranial fossils (teeth) were found at latitude $29^{\circ} 41^{\prime} 01^{\prime \prime} \mathrm{N}$, and longitude $69^{\circ} 23^{\prime} 59^{\prime \prime} \mathrm{E}$ of Alam 19 type locality (Figure 4) of Vitakri dome area, Barkhan district, Balochistan province, Pakistan. The host horizon is the Vitakri Formation (Figure 3) of Fort Munro Group [6]. Its age is the latest Maastrichtian [13].

Diagnosis and comparison: Vitakridrinda sulaimani overlapping features with Abelisauroidea Ceratosauria are as broad, small and low crown teeth, large hollow cavity enveloped by thick peripheral limb bones and medium to large sized amphicoelous vertebrae. Vitakridrinda sulaimani shares with Vitakrisauridae the amphicoelous vertebrae with anteriorly inserted neural arch, small and large canine teeth. Vitakridrinda sulaimani has short, anteroposteriorly broad, oval to subcircular shaped and recurved teeth, while Gspsaurus and Saraikimasoom have long slender and circular to subcircular teeth. Comparison with titanosaur made due to associated finding (with titanosaur, mesoeucrocodile, bird and snake). About ten teeth of theropods found which were previously assigned to Induszalim mesoeucrocodile. These teeth have longitudinal and irregular lineated structures. The tooth central cavity is significantly large than the covering enamel. The enamel thickness is roughly same on the cross section (Figure 9). Vitakridrinda sulaimani has short and broad oval teeth matching with Indosuchus raptorius. Vitakridrinda also has subcircular teeth while Vitakrisaurus and Indosuchus has oval shaped teeth convexing lingually and labially (Rajasaurus 
has no preserved teeth for comparison). Vitakridrinda teardrop type teeth like Rahiolisaurus, but differ in subcircular shape. Vitakridrinda has D-shaped and subcircular teeth while Rahiolisaurus has symmetrical cross sectional shape of teeth. The diagnosis and comparisons of postcranial materials can be seen in pages 512-520 of [28].

\subsection{Mesoeucrocodiles from Latest Maastrichtian of Pakistan}

The following four mesoeucrocodiles reported from the terrestrial fluvial Vitakri Formation of latest Maastrichtian age. While the Khuzdarcroco zahri based on a partial rib GSP/MSM-1057-K (Figure 10) was found from the Early to mid Cretaceous Goru Formation of Parh Group in Khuzdar area of the Kirthar foldbelt (south Indus basin) just close to western Indus suture [20].

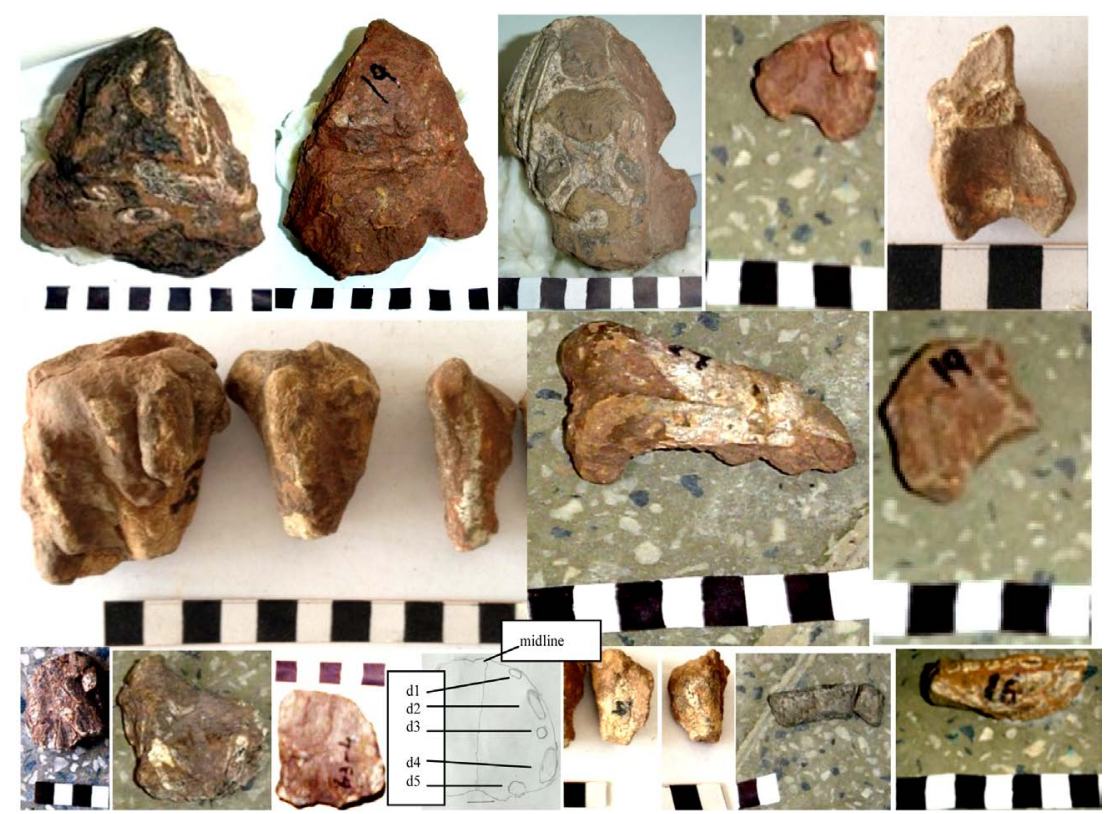

Figure 10. Induszalim bala holotypic materials (row 1 and 2) found from Alam 19 (Alam central 19c) type locality (Figure 4), Barkhan district, Balochistan Province, Pakistan. Sulaimanisuchus kinwai holotypic materials (photo/p1,2,3,4,5 and 6 of row 3) found from south Kinwa 4 locality (Figure 4), Barkhan district, Balochistan Province, Pakistan. Khuzdarcroco zahri holotypic materials (p7 of row 3) found from Khuzdar locality (for location see in Figure 1 of [10]), Khuzdar district, Balochistan. Saraikisaurus minhui holotypic beak (p8 or last photo of row 3 ) found from Top Kinwa 16 (Figure 4), Barkhan District, Balochistan Row 1, Induszalim bala holotype rostrum GSP/MSM-155-19 (=MSM-155-19c due to central Alam), in left lateral, right lateral and posterior views, and caudal vertebrae GSP/MSM-1084-19, GSP/MSM-65-19. Row 2, Induszalim bala holotypic proximal left tibia articulated with proximal left fibula GSP/MSM-1086-19, proximal left ulna GSP/MSM-1120-19 and proximal left humerus GSP/MSM-1087-19; distal and mid left femur GSP/MSM-66-19 and ilium/proximal humerus GSP/MSM-1088-19. Row 3, p1,2,3,4, Sulaimanisuchus kinwai holotypic dentary GSP/MSM-63-4 images in 3 views and line drawing of nearby image 3, and p5,6, holotypic proximal humerus GSP/MSM1094-4 in 2 views. P7, Khuzdarcroco zahri holotypic partial rib GSP/MSM-1057-K. P8, Saraikisaurus minhui holotypic lower beak/dentary ramus MSM-157-16 with articulated teeth. Scale, every black or white digit is $1 \mathrm{~cm}$. 


\subsubsection{Pabwehshi pakistanensis Mesoeucrocodile from Pakistan}

Pabwehshi pakistanensis [30] was a medium to large sized Induszalimidae mesoeucrocodiles based on holotypic rostrum GSP/MSM-6-3 (GSP-UM-2001) found from Topkinwa or Top Kinwa 16 type locality (latitude $29^{\circ} 41^{\prime} 17^{\prime \prime} \mathrm{N}$; longitude $69^{\circ} 24^{\prime} 00^{\prime \prime} \mathrm{E}$ ), Barkhan district, Balochistan province, Pakistan.

\subsubsection{Induszalim bala Mesoeucrocodile from Pakistan Systematic paleontology: \\ Crocodyliformes [31]; \\ Mesoeucrocodylia [32]; \\ Induszalimidae new family.}

Definition: Induszalim, Pabwehshi; their most recent common ancestor and all of its descendants.

Included species: Induszalim bala and Pabwehshi pakistanensis.

Diagnosis: Features same as type species Induszalim bala.

Induszalim bala new genus and new species.

(Figure 10)

Etymology: Indus, in honor of host Indus basin and Indus River, zalim, Ur$\mathrm{du} /$ Saraiki language meaning cruel. The species name bala, Saraiki language meaning big terrible animal.

Holotype: Rostrum GSP/MSM-155-19, caudal vertebrae GSP/MSM-65-19 and GSP/MSM-1084-19, proximal left tibia articulated with proximal left fibula GSP/MSM-1086-19, proximal left ulna GSP/MSM-1120-19, proximal left humerus GSP/MSM-1087-19, distal and mid left femur GSP/MSM-66-19, and ilium MSM1088-19 (Figure 10). All these fossils are housed in the museum of Geological Survey of Pakistan, Quetta. These holotypic materials are found as surface finds in the same formation, same site, fit size and no duplication shows associated bones of a single individual.

Referred specimens: A dorsal vertebra GSP/MSM-64-15 from Mari Bohri locality 15 was referred [28].

Type locality, horizon and age: The holotype was discovered in Alam 19 or central Alam 19c (latitude 29 $41^{\prime} 01^{\prime \prime N}$; longitude 69 $23^{\prime} 59^{\prime \prime} \mathrm{E}$ ) (Figure 4) of Vitakri area, Barkhan district, Balochistan. The host horizon is the Vitakri Formation (Figure 3) of Fort Munro Group [6]. Its age is the latest Maastrichtian [13].

Diagnosis: Induszalim bala secondary plate shares with the mesoeucrocodilean crocodyliform. External nare is sub terminal while Pabwehshi has terminal nare and Mithasaraikistan has forwardly inserted terminal nare. Anterior rostrum is moderately inclined, while it is vertical in Pabwehshi pakistanensis. Stepped premaxilla strip has found anterior to narial fossa, while Pabwehshi pakistanensis have no step. Splenial and dentary are united as concavo-convexo style with axis in mid while its axis is shifted ventrally in Pabwehshi. Induszalim dentary has large pneumatopores while Pabwehshi dentary has small pneumatopores. Its detail diagnosis can be seen in [28]. 
Description: It is first described and figured in conference 2014 [33] and later on described and figured in 2015 [20]. Its updated description regarding the above materials can be seen in [28].

\subsubsection{Sulaimanisuchus kinwai Mesoeucrocodile from Pakistan}

Systematic paleontology:

Crocodyliformes [31];

Mesoeucrocodylia [32];

Sulaimanisuchidae new family.

Definition: Sulaimanisuchus, their most recent common ancestor and all of its descendants.

Included species: Sulaimanisuchus kinwai.

Diagnosis: Features same as type species Sulaimanisuchus kinwai.

Sulaimanisuchus kinwai new genus and new species.

(Figure 10)

Etymology: Sulaimani, in honor of host Sulaiman basin, suchus, Greek meaning crocodile. The species name kinwai honors the Kinwa water spring.

Holotype: Dentary GSP/MSM-63-4 and proximal humerus GSP/MSM-1094-4 (Figure 10). All these fossils are housed in the museum of Geological Survey of Pakistan, Quetta. This holotypic materials were found as surface finds (with about $5 \mathrm{~m}$ separation) at the same time in the same formation, same site, fit size and no duplication shows associated bones of a single individual.

Type locality, horizon and age: The holotype was discovered in south Kinwa 4 or $4 \mathrm{~s}$ (latitude $29^{\circ} 41^{\prime} 00^{\prime \prime} \mathrm{N}$; longitude $69^{\circ} 23^{\prime} 10^{\prime \prime} \mathrm{E}$ ) (Figure 4 ) of Vitakri area, Barkhan district, Balochistan. The host horizon is the Vitakri Formation (Figure 3) of Fort Munro Group [6]. Its age is the latest Maastrichtian [13].

Diagnosis and comparisons: Sulaimanisuchus kinwai shares with the mesoeucrocodilean crocodyliform as the widely spaced teeth on lower jaw; butt sutures; large diastema after the $4^{\text {th }}$ dentary tooth; and the fit size. Sulaimanisuchus kinwai autapomorphies are as below. Its dentary $4^{\text {th }}$ tooth is large while in Pabwehshi it is small. Sulaimanisuchus kinwai has large $4^{\text {th }}$ dentary tooth like Kinesuchus overoi, Osteolaemus tetraspis, Pehuenchesuchus enderi, Gasparinisuchus peirosauroides, Morrinhosuchus luziae and Montealtosuchus arrudacamposi but vary in sizes in $1^{\text {st }}, 2^{\text {nd }}$ and $3^{\text {rd }}$ dentary teeth. Sulaimanisuchus kinwai $\mathrm{d} 1$ is small like Pabwehshi. Its $\mathrm{d} 2$ is large while Pabwehshi has relatively small d2. Its $\mathrm{d} 3$ is small while Pabwehshi has relatively very large d3. Its $\mathrm{d} 4$ is large and on teeth alignment, while Pabwehshi has relatively very small $\mathrm{d} 4$ and located medially. Its $\mathrm{d} 5$ is relatively large and more medially set just close to splenial contact, while Pabwehshi has relatively very small d5 and away from splenial contact. Sulaimanisuchus has transversely compressed teeth while Mithasaraikistan has circular and subcircular teeth. Sulaimanisuchus has slightly broad anterior jaw while Mithasaraikistan has relatively broader anterior jaw.

Description: Its holotype was described in 2010 [29] and in 2020 in pages 
543-545 of [28]. For comparisons, see as above and also in [28].

\subsubsection{Mithasaraikistan ikniazi Mesoeucrocodile from Pakistan}

Systematic paleontology:

Crocodyliformes [31];

Mesoeucrocodylia [32];

Mithasaraikistanidae new family.

Definition: Mithasaraikistan; their most recent common ancestor and all of its descendants.

Included species: Mithasaraikistan ikniazi.

Diagnosis: Features same as type species Mithasaraikistan ikniazi.

Mithasaraikistan ikniazi, new genus and new species.

(Figure 11)

Etymology: Mitha, Saraiki language meaning sweat, saraikistan, in honor of Saraiki people, Saraiki region (wasabi) called Saraikistan. The species name ikniazi, in honor of Imran Khan Niazi the prime minister of Pakistan who took a

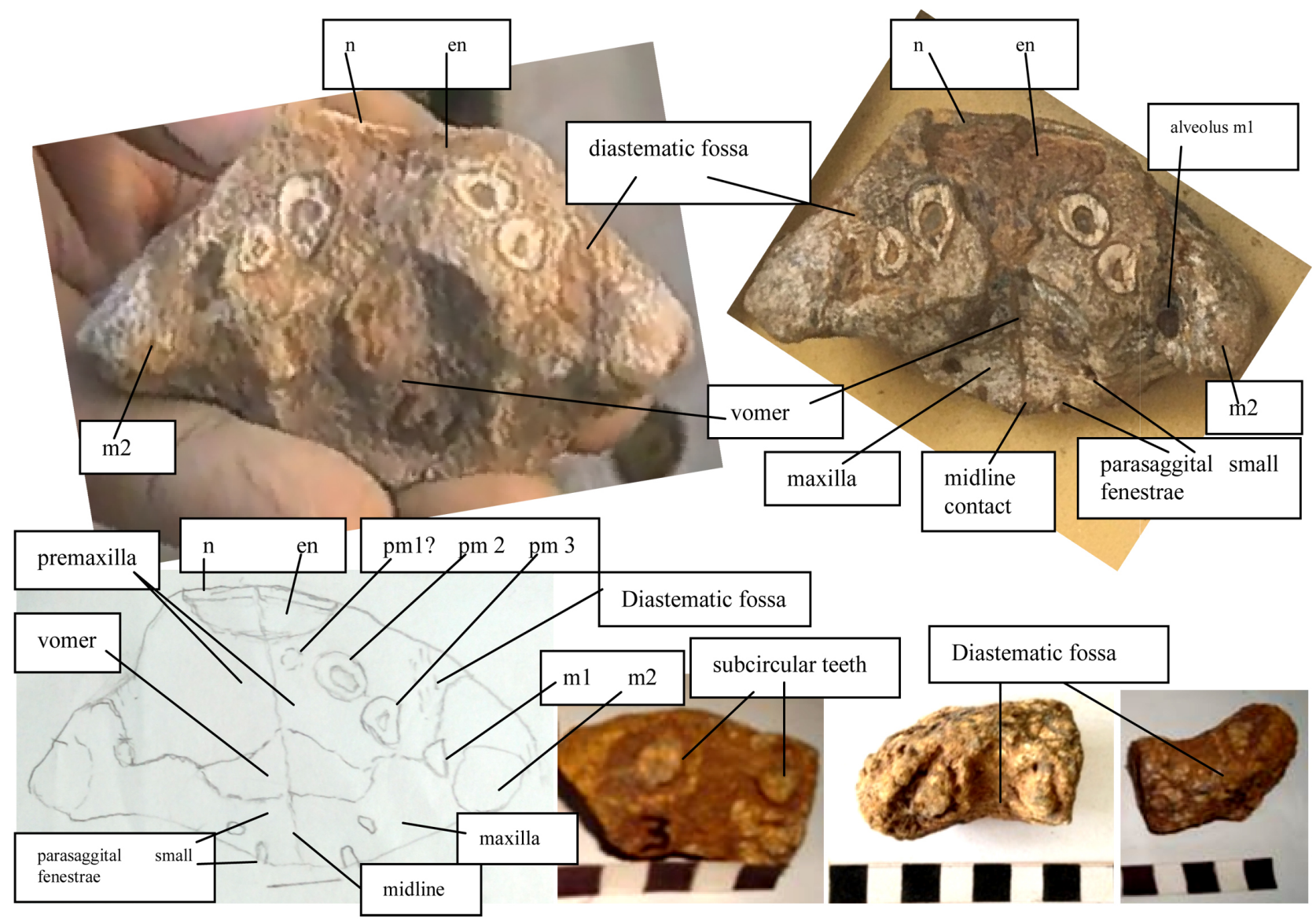

Figure 11. Mithasaraikistan ikniazi holotypic materials found from Shalghara 3 type locality (Figure 4), Barkhan district, Balochistan, Pakistan. Row 1, Holotypic snout GSP/MSM-4-3 in 2 views. Row 2, Line drawing of snout GSP/MSM-4-3 (scale bar is 1 $\mathrm{cm}$ ); holotypic dentary ramus with two teeth sandwiched between a diastema GSP/MSM-139-3 in 3 views. Scale, each black or white digit is $1 \mathrm{~cm}$. Abbreviations; en-external naris, m1-maxillary tooth 1, m2-maxillary tooth 2, n-nasal, pm1-premaxillary tooth 1, pm2-premaxillary tooth 2, pm3-premaxillary tooth 3 . 
sincere interest and a step for the creation of South Punjab Province (Saraikistan Province). Pronunciation of ikniazi is i.k.niazi (the abbreviation of Imran Khan Niazi). Here the name Mithasaraikistan used for the sweat (animal) of Saraikis$\tan$.

Holotype: Snout GSP/MSM-4-3, and dentary ramus GSP/MSM-139-3 (Figure 11). The fossils are housed in the museum of Geological Survey of Pakistan, Quetta. The holotypic fossils were found as fragmentary in the same formation, same site, fit size and fit features shows associated skeleton of an individual.

Type locality, horizon and age: The holotype was discovered in Shalghara 3 type locality at latitude $29^{\circ} 40^{\prime} 56^{\prime \prime} \mathrm{N}$, and longitude $69^{\circ} 22^{\prime} 47^{\prime \prime}$ (Figure 4) of Vitakri dome area, Barkhan district, Balochistan. The host horizon is the Vitakri Formation (Figure 3) of Fort Munro Group [6]. Its age is latest Maastrichtian [13].

Diagnosis: The large diastema between premaxilla and maxilla, terminal nares, reduced anterior portion of rostrum including only 3 premaxillary teeth, butt sutures and size along with the age latest Cretaceous points toward medium to large mesoeucrocodilean Crocodyliformes. On low and broad rostrum it matches with Malawisuchus, and Itasuchus which is considered a typical peirosaurids [34] but differ in premaxillary teeth counting and morphology. Mithasaraikistan ikniazi has relatively very broad rostrum, distinct teeth orientation, size and shape differ from uruguaysuchid, peirosaurid, notosuchids, baurusuchid, Induszalimidae and Sulaimanisuchidae, so being assigned a new family Mithasaraikistanidae. The autapomorphies of Mithasaraikistan ikniazi are as below. Very broad and low rostrum while Pabwehshi and Induszalim have deep rostrum; D-shaped teeth with outer planar and inner convex surface and also round circular teeth with thick enamel, while Pabwehshi, Induszalim and Sulaimanisuchus have oval and D-shaped teeth with planar lingual surface and convex labial surface; a reduced anterior part of snout with only 3 premaxillary teeth, in which $2^{\text {nd }}$ premaxillary tooth is enlarged while in Pabwehshi the $3^{\text {rd }}$ premaxillary tooth is enlarged; $1^{\text {st }}$ maxillary tooth is D-shaped while it is oval in Pabwehshi; $2^{\text {nd }}$ maxillary tooth is circular, while it is oval in Pabwehshi; $1^{\text {st }}$ premaxillary tooth is situated on teeth alignment, while Pabwehshi has dorsally inset; It bears no diastematic fossa between the $2^{\text {nd }}$ and $3^{\text {rd }}$ premaxillary teeth while Pabwehshi shows a diastematic fossa between $2^{\text {nd }}$ and $3^{\text {rd }}$ premaxillary teeth; It has no large fenestra on the suture of premaxilla and maxilla, while Pabwehshi has a large fenestra; it has concavo-convexo shape vomer with posterior plane as concave surface (for the Adjustment of maxilla) and anterior convex shape convexing anteriorly (for contact with premaxilla), while Pabwehshi has generally convexing both surfaces (biconvex), and its jaw margins drops sharply at the midline contact on anteriormost extremity while in Pabwehshi the jaw margins convexing anteriorly.

Mithasaraikistan ikniazi has broad rostrum while Uberabasuchus terrificus, Itasuchus jesuinoi, Baurusuchus pachecoi, Mariliasuchus amarali, Araripesuchus patagonicus, Notosuchus terrestris, Adamantinasuchus navae, Gondwanasuchus scabrosus, Caipirasuchus montealtensis, Caipirasuchus paulistanus, Morrinho- 
suchus luziae, Simosuchus clarki, Pabwehshi pakistanensis and Induszalim bala have deep rostrum. Mithasaraikistan ikniazi has broad anterior rostrum with forwardly inserted nasal like Montealtosuchus arrudacamposi and Montealtosuchus arrudacamposi but differ in premaxillary teeth count and size variation. Mithasaraikistan ikniazi has broad rostrum like Araripesuchus tsangatsangana, Miadanasuchus oblita, Mahajangasuchus insignis, Stratiotosuchus maxhechti, Sphagesaurus huenei, Comahuesuchus brachybuccalis, Cynodontosuchus rothi and Lomasuchus palpebrosus but differ in nasal orientation, premaxillary teeth count and size variations. Mithasaraikistan ikniazi has 3 premaxillary teeth while Stratiotosuchus maxhechti and Gasparinisuchus peirosauroides has 4 or 5 premaxillary teeth.

Description: The holotypic snout GSP/MSM-4-3 preserving almost complete premaxillae, a small part of maxillae, partial nasal, complete vomer and teeth in place. Premaxilla forms the side wall and part of palate of anteriormost part of rostrum. This rostrum is strongly broad and low than the Pabwehshi and Induszalim both have deep rostrum. Premaxilla is triangular (Figure 11). A diastematic fossa found on the contact of premaxilla and maxilla which receives the large caniniform crown of dentary tooth. Premaxilla bears 3 teeth that increase in size from $1^{\text {st }}$ to $2^{\text {nd }}$ but decrease in size from $2^{\text {nd }}$ to $3^{\text {rd }}$ premaxillary teeth, while in Pabwehshi premaxillary teeth increase in size from $1^{\text {st }}$ to $3^{\text {rd }}$ premaxillary teeth. The $1^{\text {st }}$ premaxillary tooth may be small. The jaw margins are convex outside lateral to $2^{\text {nd }}$ premaxillary larger tooth while Pabwehshi jaw margins are nearly plain lateral to $2^{\text {nd }}$ premaxillary medium sized tooth. Left and right premaxillae contact with each other as butt midline. Premaxillary portion of palate contacts the maxillary portion of palate along a transversely oriented zig-zag butt suture which is interrupted centrally by the vomer and not any fenestra, while in Pabwehshi it is also interrupted by a vomer and a large fenestra. The $3^{\text {rd }}$ premaxillary and $1^{\text {st }}$ maxillary asymmetric $\mathrm{D}$-shape teeth have plain labial side and convex toward lingual side. The $1^{\text {st }}$ premaxillary tooth is small and circular to subcircular (Figure 11), while Pabwehshi has small and transversely compressed. The $2^{\text {nd }}$ premaxillary tooth is large and circular to subcircular (Figure 11), while Pabwehshi has small and transversely compressed $2^{\text {nd }}$ premaxillary tooth. It has reduced premaxilla with only three teeth. The $1^{\text {st }}$ premaxillary tooth seems to be about half of the $2^{\text {nd }}$ premaxillary tooth. The $2^{\text {nd }}$ premaxillary tooth is about $8 \mathrm{~mm}$ (millimeter) long anteroposteriorly and $7 \mathrm{~mm}$ wide transversely, and the $3^{\text {rd }}$ premaxillary tooth is about $7 \mathrm{~mm}$ long anteroposteriorly and $6 \mathrm{~mm}$ wide transversely.

Maxilla is started posteriorly from the diastematic fossa. The $1^{\text {st }}$ maxillary tooth is D-shaped and relatively small and the $2^{\text {nd }}$ maxillary tooth is circular and large while Pabwehshi have oval shaped these teeth. Maxillae form the side walls of rostrum and part of palate just behind the premaxillae. Two fellows of maxilla forms midline butt contact. The $2^{\text {nd }}$ maxillary tooth is expanded laterally. Two pair of small paramedian or parasaggital fenestrae found in the maxillae located 
close to midline (Figure 11), while Pabwehshi bears no any small fenestra in maxilla. One pair of small fenestra is found close to midline while second pair is relative away from midline (Figure 11).

A small vomer is located medially on midline between the premaxillae and maxillae on the palatal. Vomer is concavo-convexo shaped (Figure 11) while it is diamond shaped in Pabwehshi. Vomer forms convex shape anteriorly forming contact with premaxilla, while vomer forms concave shape posteriorly for the articulation with maxilla.

Nasal is forwardly inserted and forms the roof of snout. Nasals cover the external naris dorsally while laterally covered by premaxilla (Figure 11). Internarial bar is not preserved or may be destroyed. External nares faced anteriorly. For other comparison, see in diagnosis.

\subsection{Pterosaur (the Flying Reptile) from Pakistan}

Systematic paleontology:

Pterosauria [35];

Pterodactyloidea [36];

Saraikisauridae new family;

Definition: Saraikisaurus, their most recent common ancestor and all of its descendants.

Included species: Saraikisaurus minhui.

Diagnosis: Features same as type species Saraikisaurus minhui.

Saraikisaurus minhui new genus and new species.

(Figure 10)

Etymology: Saraiki, in honor of Saraiki people and language, saurus, Greek for lizard. Species name minhui honors the Prof. Dr. Min Huh of Korea Dinosaur Research Centre and Chonnam National University, Gwanju, South Korea for his kind support to the visit of Mesozoic Terrestrial Ecosystems of South Korea.

Holotype: Dentary ramus GSP/MSM-157-16 (Figure 10) belongs to a single individual. Fossil is housed in museum of Geological Survey of Pakistan, Quetta.

Referred specimens: A few fossils from India were referred [28].

Type locality, horizon and age: Holotype was discovered in Top Kinwa 16 locality (Figure 4), Barkhan District, Balochistan. The host horizon is the Vitakri Formation (Figure 3) of Fort Munro Group [6]. Its age is the latest Maastrichtian [13]. The grid reference of the Top Kinwa 16 (Topkinwa 16) type locality are latitude $29^{\circ} 41^{\prime} 17^{\prime \prime} \mathrm{N}$, and longitude $69^{\circ} 24^{\prime} 00^{\prime \prime} \mathrm{E}$.

Diagnosis: Saraikisaurus minhui shares with Pterodactyloidea as slender relatively thin beak. Saraikisaurus minhui autapomorphies are as below. It has pneumatic and narrow dentary with partially overlapped oval teeth showing large number of teeth contrary to other coeval pterosaurs. Its diagnosis and comparison is provided in pages 545-546 of [28].

Description: It was first reported in 2013 [37] and later on described and figured in 2019 in pages $936-937$ of [4] and in pages 545-546 of 2020 [28]. 


\subsection{New Snake from the Latest Maastrichtian of Pakistan}

Systematic paleontology:

Squamata [38];

Ophidia [39];

Madtsoiidae [40] [41];

Wadanaang kohsulaimani new genus and new species.

(Figure 12)

Etymology: Wada, Saraiki language meaning big, naang, Saraiki meaning snake. The species name koh, Balochi language meaning mountain, sulaimani, in honor of the host Koh Sulaiman mountain Range and Sulaiman basin.

Holotype: Teeth (each tooth articulated with partial dentary) GSP/MSM-110219, GSP/MSM-1103-19, GSP/MSM-1104-19, GSP/MSM-1105-19, GSP/MSM1106-19 and GSP/MSM-1107-19, and a vertebra GSP/MSM-1108-19 (Figure 12). These teeth (part of teeth row) and a vertebra seem to be a part of a single individual found in block GSP/MSM-61-19. These fossils are found in a rock fragment with fit size seems to belong to a single individual. All these fossils are housed in the museum of Geological Survey of Pakistan, Quetta.

Type locality, horizon and age: The holotype was discovered in Alam 19 type locality at latitude $29^{\circ} 41^{\prime} 01^{\prime \prime} \mathrm{N}$, and longitude $69^{\circ} 23^{\prime} 59^{\prime \prime} \mathrm{E}$ (Figure 4), Barkhan district, Balochistan. The host horizon is the Vitakri Formation (Figure 3) of Fort Munro Group [6]. Its age is the latest Maastrichtian [13].

Diagnosis: The large teeth and vertebra of Wadanaang kohsulaimani snake shared with derived large mouthed snake (macrostomatans). The slender and straight teeth only recurved on tip of Wadanaang kohsulaimani snake differ from the stocky and low angle arc shaped teeth of Sanajeh indicus from India [42]. Its precloacal vertebra bears ventral keel and very broad neural canal.

Description: The large sized (about $3-4 \mathrm{~m}$ long) terrestrial gigantic snake is reported first time from the latest Cretaceous of Pakistan. This snake is preserved in extraordinary condition especially with the teeth fossils of bird and also coiling around egg of titanosaurian sauropod. This site is first among globe which revealed snake Wadanaang and bird Wasaibpanchi behavior and collision on feeding egg of titanosaurs, and the predation of theropod Vitakridrinda and mesoeucrocodile Induszalim upon the large sized titanosaurian sauropod Gspsaurus and or its nesting. This fossil block represents feeding ecological behavior and confrontation of the bird and snake which prey on egg of titanosaurs. There is paucity of Maastrichtian snake fossils globally so these fossils will broaden the distribution of snake. The fossils of Wadanaang kohsulaimani found in the fragmentary block $(8 \mathrm{~cm} \times 8 \mathrm{~cm})$ consists of variable size of elongated and narrow teeth articulated with partial fragmented dentary. The Wadanaang kohsulaimani teeth are small to large sized and elongated (Figure 12) while Sanajeh indicus [42] teeth are relatively stockier and broader. The Wadanaang kohsulaimani teeth are almost straight only slightly recurved at the tip (Figure 12) while Sanajeh indicus [42] teeth forms low angle arc shape. The Wadanaang teeth are 


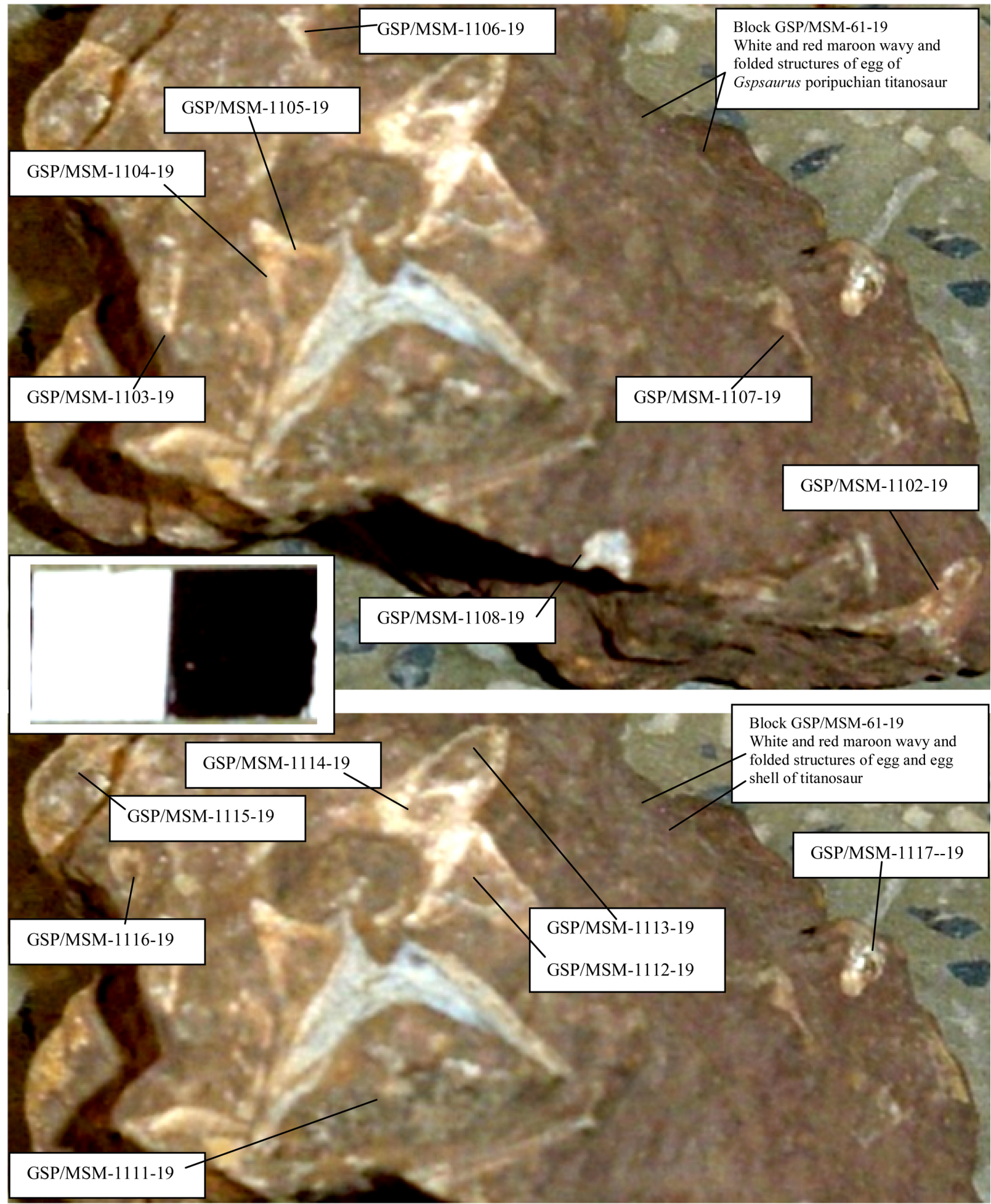

Figure 12. Upper photo, Wadanaang kohsulaimani holotypic teeth with partially articulated dentary GSP/MSM-1102-19, GSP/MSM-1103-19, GSP/MSM-1104-19, GSP/MSM-1105-19, GSP/MSM-1106-19 and GSP/MSM-1107-19 and a vertebra GSP/MSM-1108-19 found from Alam 19 type locality (Figure 4), Barkhan district, Balochistan Province, Pakistan. Lower photo, Wasaibpanchi damani holotype teeth GSP/MSM-1111-19, GSP/MSM-1112-19, GSP/MSM-1113-19, GSP/MSM1114-19, GSP/MSM-1115-19, GSP/MSM-1116-19 and GSP/MSM-1117-19 found from Alam 19 type locality (Figure 4), Barkhan district, Balochistan Province, Pakistan. All these fossils are found in titanosaurian sauropod egg block GSP/MSM61-19. Scale, each black or white digit is $1 \mathrm{~cm}$. 
mostly long conical type; it means the thickness is decreasing from base to upward gradually. Its relatively longer two teeth GSP/MSM-1102-19 and GSP/ MSM-1103-19 measured upto $0.7 \mathrm{~mm}$ length and $2-2.5 \mathrm{~mm}$ mid exposed width (belong to anterior portion of teeth row), its moderate size two teeth GSP/MSM1104-19 and GSP/MSM-1105-19 measured upto $0.5 \mathrm{~mm}$ length and $1.5 \mathrm{~mm}$ width (belong to mid part of teeth row), and its relatively two small teeth GSP/MSM1106-19 and GSP/MSM-1107-19 measured 0.3 mm length and about $1 \mathrm{~mm}$ width (belong to distal part of teeth row). The partial dentary ramus is articulated on the base of teeth. The precloacal centrum GSP/MSM-1108-19 is broad about 4 $\mathrm{mm}$ wide and $3 \mathrm{~mm}$ high. This precloacal vertebra characterized by very broad neural canal. The exposed view of vertebra show possibly haemal keel (ventral keel) on the centrum. The long and slender teeth of Wadanaang kohsulaimani snake show derived large mouthed snake (macrostomatans). The partial and fragmented lower jaw of Wadanaang derived snake shows it can eat large vertebrates while basal snakes prey only on small animals. The block size and fine folded white and red/maroon structures in the block GSP/MSM-61-19 egg of titanosaurian sauropod (Figure 12). This block represents the egg feeding history and collision behavior of Maastrichtian snake Wadanaang and bird Wasaibpanchi from Pakistan. Further this block and nearby associated finding of rostrum of mesoeucrocodile Induszalim and teeth of theropod Vitakridrinda and partial skeleton of titanosaur Gspsaurus revealed parental care for egg and nesting, the predatory behavior of theropod and mesoeucrocodile upon large herbivore titanosaurian sauropod Gspsaurus pakistani and consequent their death.

\subsection{New Bird (Avian) from Latest Cretaceous of Pakistan}

\section{Systematic paleontology:}

Aves;

Metornithes [43] (Maniraptora is synonym of Metornithes);

Ornithotharaces [44];

Enantiornithes [45];

Wasaibpanchidae new family.

Definition: Wasaibpanchi; their most recent common ancestor and all of its descendants.

Included species: Wasaibpanchi damani.

Diagnosis: Feature as for type species Wasaibpanchi damani.

Wasaibpanchi damani new genus and species.

(Figure 12)

Etymology: Wasaib, Saraiki language meaning the living culture and area of Saraiki people (which host fossils), panchi, in Saraiki language meaning bird. The species name damani honors the Daman area (foot belt of Koh Sulaiman mountain Range) which hosts mostly the Saraiki and Balochi peoples.

Holotype: Teeth GSP/MSM-1111-19, GSP/MSM-1112-19, GSP/MSM-1113-19, GSP/MSM-1114-19, GSP/MSM-1115-19, GSP/MSM-1116-19 and GSP/MSM- 
1117-19 (Figure 12). These teeth seem to be a part of teeth row of a single individual found in fragmentary block GSP/MSM-61-19 and due to morphology of teeth. Fossils are housed in museum of Geological Survey of Pakistan, Quetta.

Type locality, horizon and age: The holotype was discovered in Alam 19 type locality at latitude $29^{\circ} 41^{\prime} 01^{\prime \prime} \mathrm{N}$, and longitude $69^{\circ} 23^{\prime} 59^{\prime \prime E}$ (Figure 4), Barkhan district, Balochistan. The host horizon is the Vitakri Formation (Figure 3) of Fort Munro Group [6]. Its age is the latest Maastrichtian [13].

Diagnosis: Wasaibpanchi damani light teeth and very thin enamel around large cavity of teeth shared to Enantiornithes birds. Wasaibpanchi damani is characterised as below. Its teeth are sharp trigonal with low crown. Its teeth enamel is very thin as compared to mesoeucrocodiles like Pabwehshi pakistanensis and theropod like Vitakridrinda sulaimani and also pterosaur like Saraikisaurus minhui; Its teeth are trigonal (with triconvex cross section), while theropods, mesoeucrocodiles and pterosaurs from Pakistan mostly have oval to circular tooth cross sectional shape; its thickness of enamel which is increasing toward distal and mesial corners of teeth which differentiate it from the teeth of Vitakridrinda theropod (Figure 9), Mithasaraikistan (Figure 11) and other mesoeucrocodiles (Figure 10) and Saraikisaurus (Figure 10) pterosaur from Pakistan.

Description: The fossils of large sized bird are being reported first time from the latest Maastrichtian of Pakistan. Wasaibpanchi damani teeth are anteroposteriorly broad and transversely compressed with low crown with triconvex cross section. Asymmetric trigonal teeth show asymmetric sharp convexity on one side, and plain surface on another side. Its larger teeth cavity is enveloped by blue thin enamel layer and then outer thin white enamel layer, while theropods and mesoeucrocodiles from Pakistan have relatively thick enamel on short cavity. The enamel thickness is increasing toward distal corner like toward mesial and distal end of teeth. This feature again differentiates it from the teeth of Vitakridrinda theropod (Figure 9), Mithasaraikistan (Figure 11) and other mesoeucrocodiles (Figure 10) and Saraikisaurus (Figure 10) pterosaur. The Wasaibpanchi damani teeth are trigonal while Saraikisaurus pterosaur has transversely compressed oval teeth. The Wasaibpanchi damani has varying size of teeth ranging from large to small teeth. The variability of teeth size from large to small of latest Maastrichtian Wasaibpanchi damani matches with the Pelagornis-a late Tertiary bird which also has large and small teeth, suggesting Wasaibpanchi to be ancestor. This block GSP/MSM-61-19 consists of fossils of Wasaibpanchi bird, Wadanaang snake and portion of egg of Gspsaurus titanosaur, which found in association with rostrum and postcrania of Induszalim mesoeucrocodile, teeth of Vitakridrinda theropod and partial skull (snout and associated elements in two pieces) of Gspsaurus titanosaur. This block reveals the ecological feeding history and behavior of snake and bird on titanosaur egg and their fighting upto death. This site also revealed the titanosaurian parental care for its egg (and nesting), the predation of theropod and mesoeucrocodile on large titanosaur and consequent their death possibly by collision. 


\subsection{Footprints and Trackways of Mesozoic Vertebrates Found from Pakistan}

The latest Jurassic Samanasuk Limestone of north Indus basin yielded tracks and trackways of Samanadrinda surghari large theropod confronted on a herd of Malakhelisaurus mianwali herbivorous stocky Titanosauriformes or stegosaurs/ hadrosaurs and trackways of a couple of Himalayadrinda potwari small theropods [4] [46] [47] [48]. The latest Cretaceous tracks of Pashtosaurus zhobi [4] [19] [20] stocky titanosaurs/larger ornithischian like hadrosaurs, stegosaurs along with a few tracks of Anmolpakhi alleni pterosaurs were found in the Pab Formation of Sor Muzghai-Musafar Pur locality of Qila Saifullah district, Zhob division, Balochistan, and a single natural cast of footprint of Dgkhansaurus maarri [4] titanosaurian sauropod in the uppermost part of Maastrichtian Pab Formation of Maarri peak area of Rajanpur district of South Punjab (Saraikistan). Pashtosaurus zhobi found in the fine sandy bed while the other conglomeratic bed shown in Figure 3 of [20] is not the host which creates ambiguity regarding the biologic origin of footprints (wrongly as conglomeratic origin). Further a single small pes footprint of Late-latest Jurassic Titanosauriformes named as Chiltanpaer nicki (Figure 5) found from the Moola Kharzan area, Khuzdar district, Balochistan was first reported in Figure 5 of [7]. Chiltanpaer honors the host Chiltan Formation and paer in Saraiki/Urdu language for foot. Species name nicki honors the British Journalist Nicholas Allen who helped a lot for the preservation of Mesozoic vertebrates' footprints from Pakistan. Chiltanpaer nicki have thick elongated unguals, while Dgkhansaurus maarri has slender elongated ungual, Pashtosaurus zhobi and Malakhelisaurus mianwali footprints have oval shaped wide unguals. Chiltanpaer shows digit I and digit II directed medially, the digit III anteriorly and digit IV and digit V laterally outward, in this regards matching with Malakhelisaurus mianwali and Pashtosaurus zhobi. While Dgkhansaurus maarri all unguals tilted laterally. Chiltanpaer nicki seems to be ancestor of Dgkhansaurus maarri. Trackmaker step made depression by compressing cohesive calcareous mud which extruded on the sides. During diagenesis the calcareous mud converted into limestones, which are thrusted later on by tectonics and upper bed having footprint exposed. The diagenesis is mistyped as diagnosis in the footprints and trackways of Mesozoic archosaurs from Pakistan described in 2019 [4]. It is necessary to mentioned that the names of ichnotaxa from the Mesozoic of Pakistan was renamed as ending podus [4] but here this action is being cancelled and original name remained same because these taxa are vastly used in literature.

\section{Conclusion}

The marine and terrestrial $\mathrm{J} / \mathrm{K}$ and $\mathrm{K} / \mathrm{Pg}$ boundaries are widely exposed in the Indus basin of Pakistan. The $\mathrm{J} / \mathrm{K}$ transition host few bones of titanosauriforms/basal titanosaurs. The latest Maastrichtian start just below the $\mathrm{K} / \mathrm{Pg}$ boundary represents vast exposures that host diverse archosaurs in the Barkhan district of Balochistan. 


\section{Acknowledgements}

This work is a contribution to Geological Survey of Pakistan.

\section{Conflicts of Interest}

The author declares no conflicts of interest regarding the publication of this paper.

\section{References}

[1] Fatmi, A.N. (1968) The Paleontology and Stratigraphy of the Mesozoic Rocks of Western Kohat, Kala Chitta, Hazara and Trans-Indus Salt Ranges, West Pakistan. Ph.D. Thesis, Unpub., University of Whales, Cardiff, 409 p.

[2] Fatmi, A.N. (1977) Mesozoic. In: Shah, S.M.I., Ed., Stratigraphy of Pakistan, Memoir 12, Geological Survey of Pakistan, Quetta, 29-56.

[3] Jones, A.G., Manistere, B.E., Oliver, R.L., Wilson, G.S. and Scott, H.S. (1961) Reconnaissance Geology of Part of West Pakistan (Colombo Plan Cooperative Project Conducted and Compiled by Hunting Survey Corporation). Government of Cana$\mathrm{da}$, Toronto, $550 \mathrm{p}$.

[4] Malkani, M.S. (2019) Recently Discovered Basilosaurid, Baluchithere Rhinoceros, Horses, Sea Cow, Proboscidean, Eucrocodile, Pterosaurs, Plesiosaur, Fishes, Invertebrates and Wood Fossils, Tracks and Trackways of Dinosaurs from Pakistan; Comparison of Recognized Four Titanosaur Taxa of Indo-Pakistan with Madagascar. Open Journal of Geology, 9, 919-955. https://doi.org/10.4236/ojg.2019.912098

[5] Malkani, M.S. (2006) Lithofacies and Lateral Extension of Latest Cretaceous Dinosaur Beds from Sulaiman Foldbelt, Pakistan. Sindh University Research Journal (Science Series), 38, 1-32.

[6] Malkani, M.S. (2009) New Balochisaurus (Balochisauridae, Titanosauria, Sauropoda) and Vitakridrinda (Theropoda) Remains from Pakistan. Sindh University Research Journal (Science Series), 41, 65-92.

[7] Malkani, M.S. (2010) New Pakisaurus (Pakisauridae, Titanosauria, Sauropoda) Remains, and Cretaceous Tertiary (K-T) Boundary from Pakistan. Sindh University Research Journal (Science Series), 42, 39-64.

[8] Malkani, M.S. (2019) Cretaceous Stratigraphy of Pakistan. Open Journal of Geology, 9, 671-673. https://doi.org/10.4236/ojg.2019.910071

[9] Malkani, M.S. and Mahmood, Z. (2017) Stratigraphy of Pakistan. Geological Survey of Pakistan, Quetta, Memoir Volume 24, 1-134.

[10] Malkani, M.S. (2003) First Jurassic Dinosaur Fossils Found from Kirthar Range, Khuzdar District, Balochistan, Pakistan. Geological Bulletin, University of Peshawar, 36, 73-83.

[11] Malkani, M.S. (2020) First Skull of Medium Sized Titanosaur from Indo-Pakistan Subcontinent Found from Found from the Latest Maastrichtian Vitakri Formation of Pakistan; Associated Cranial and Postcranial Skeletons of Gspsaurus pakistani (Poripuchia, Stocky Titanosauria, Sauropoda) from Pakistan and India. Open Journal of Geology, 10, 448-489. https://doi.org/10.4236/ojg.2020.104020

[12] Malkani, M.S. (2020) First Snout with Complete Teeth Row of Titanosaur from Indo-Pakistan Subcontinent Found from the Latest Maastrichtian Vitakri Formation of Pakistan; Associated Cranial and Postcranial Skeletons of Saraikimasoom vitakri (Poripuchia, Stocky Titanosauria, Sauropoda) from Pakistan and Referred Fossils 
from India. Open Journal of Geology, 10, 368-407.

https://doi.org/10.4236/ojg.2020.104018

[13] Malkani, M.S. (2020) Pakisaurus balochistani (Poripuchia, Slender Titanosauria, Sauropoda) Associated Skeletons from the Latest Maastrichtian Vitakri Formation of Pakistan and Referred Fossils from India; Filling of Significant Missing Links of Isisaurus colberti (Poripuchia, Slender Titanosauria, Sauropoda) Found from Pakistan. Open Journal of Geology, 10, 408-447.

https://doi.org/10.4236/ojg.2020.104019

[14] Owen, R. (1842) Report on British Fossil Reptiles, Pt. II. Reptiles. Report of the British Association for the Advancement of Science, 60-204.

[15] Seeley, H.G. (1888) The Classification of the Dinosauria. Report of the British Association for the Advancement of Science, 698-699.

[16] Marsh, O.C. (1878) Principal Characters of American Jurassic Dinosaurs. Part I. American Journal of Science (Series 3), 16, 411-416.

https://doi.org/10.2475/ajs.s3-16.95.411

[17] Salgado, L., Coria, R.A. and Calvo, J.O. (1997) Evolution of Titanosaurid Sauropods I: Phylogenetic Analysis Based on the Postcranial Evidence. Ameghiniana, 34, 3-32.

[18] Bonaparte, J.F. and Coria, R.A. (1993) A New and Huge Titanosaur Sauropod from the Rio Limay Formation (Albian-Cenomanian) of Neuquen Province, Argentina. Ameghiniana, 30, 271-282.

[19] Malkani, M.S. (2014) Titanosaurian Sauropod Dinosaurs from the Latest Cretaceous of Pakistan. 2nd Symposium of IGCP 608 "Cretaceous Ecosystem of Asia and Pacific", Tokyo, 4-6 September 2014, 108-111.

[20] Malkani, M.S. (2015) Dinosaurs, Mesoeucrocodiles, Pterosaurs, New Fauna and Flora from Pakistan. Geological Survey of Pakistan, Quetta, Information Release No. 823, 1-32.

[21] Malkani, M.S. (2006) Biodiversity of Saurischian Dinosaurs from the Latest Cretaceous Park of Pakistan. Journal of Applied and Emerging Sciences, 1, 108-140.

[22] Malkani, M.S. (2004) Saurischian Dinosaurs from Late Cretaceous of Pakistan. Fifth Pakistan Geological Congress, Islamabad, 14-15 April 2004, 71-73.

[23] Malkani, M.S. (2003) Discovery of Partial Skull and Dentary of Titanosauria (Sauropod Dinosaur) from the Late Cretaceous Pab Formation of Vitakri Area, Barkhan District, Balochistan, Pakistan. Geological Bulletin, University of Peshawar, 36, 65-71.

[24] Marsh, O.C. (1881) Classification of the Dinosauria. American Journal of Science (Series 3), 23, 81-86. https://doi.org/10.2475/ajs.s3-23.133.81

[25] Marsh, O.C. (1884) Principal Characters of American Jurassic Dinosaurs. Part VIII. The Order Theropoda. American Journal of Science (Series 3), 27, 329-341. https://doi.org/10.2475/ajs.s3-27.160.329

[26] Bonaparte, J.F. (1991) The Gondwanan Theropod Families Abelisauridae and Noasauridae. Historical Biology, 5, 11-25. https://doi.org/10.1080/10292389109380385

[27] Huene, F.V. and Matley, C.A. (1933) Cretaceous Saurischia and Ornithischia of the Central Provinces of India, Paleontologia Indica, 21, 1-74.

[28] Malkani, M.S. (2020) Theropods, Mesoeucrocodiles and Pterosaurs Found from the Latest Maastrichtian Vitakri Formation of Balochistan, Pakistan; Description with Large Photographs and Comparison with Coeval Taxa from Indo-Pakistan Subcontinent. Open Journal of Geology, 10, 510-551.

https://doi.org/10.4236/ojg.2020.105023

[29] Malkani, M.S. (2010) Updated Stratigraphy and Mineral Potential of Sulaiman 
(Middle Indus) Basin, Pakistan. Sindh University Research Journal (Science Series), 42, 39-66.

[30] Wilson, J.A. Malkani, M.S. and Gingerich, P.D. (2001) New Crocodyliform (Reptilia, Mesoeucrocodylia) form the Upper Cretaceous Pab Formation of Vitakri, Balochistan (Pakistan). Contributions from Museum of Paleontology, University of Michigan, 30, 321-336.

[31] Hay, O.P. (1930) Second Bibliography and Catalogue of the Fossil Vertebrata of North America, Volume 2. Carnegie Institution of Washington, Washington DC, Publication No. 390, 1-1074.

[32] Whetstone, K.N. and Whybrow, P.J. (1983) A "Cursorial" Crocodilian from the Triassic of Lesotho (Basutoland), Southern Africa. Occasional Papers of the Museum of Natural History No. 106, University of Kansas, Lawrence, 1-37.

[33] Malkani, M.S. (2014) Theropod Dinosaurs and Mesoeucrocodiles from the Terminal Cretaceous of Pakistan. 2nd Symposium International Geoscience Program (IGCP 608) “Cretaceous Ecosystem of Asia and Pacific", Tokyo, 4-6 September 2014, 169-172.

[34] Carvalho, I.S., Ribeiro, L.C.B. and Avilla, L.S. (2004) Uberabasuchus terrificus sp. nov., a New Crocodylomorpha from the Bauru Basin (Upper Cretaceous), Brazil. Gondwana Research, 7, 975-1002. https://doi.org/10.1016/S1342-937X(05)71079-0

[35] Kaup, J.J. (1834) Versuch einer Eintheilung der Saugethiere in 6 Stamme und der Amphibien in 6 Ordnungen. Isis, 3, 311-315.

[36] Plieninger, F. (1901) Beitrage zur Kenntnis der Flugsaurier. Palaeontographica, 48, 65-90.

[37] Malkani, M.S. (2013) New Pterosaur from the Latest Cretaceous Terrestrial Strata of Pakistan. 9 th International Symposium on the Cretaceous System, Ankara, 1-5 September 2013, 62 .

[38] Oppel, M. (1811) Die Ordungen, Familien, und Gattungen der Reptilien, als Prodrom einer Naturgeschichte derselben. Joseph Lindaur, Munich, 87 p.

[39] Brongniart, A. (1800) Essai d'une classification naturalle des reptiles lere partie, Establissement des Orders. Bulletin des Sciences par la Societe Philomatique, Paris, 11, 81-82.

[40] Hoffstetter, R. (1961) Noveaux restes d'un serpent Boide (Madtsoia madagascariensis nov. sp.) dans le Cretace superieur de Madagascar. Bulletin du Museum National d Histoire naturellie, Serie 2, Paris, 33, 152-160.

[41] McDowell, S.B. (1987) Systematics, In: Seigel, R.A., Collins, J.T. and Novak, S.S., Eds., Snakes Ecology and Evolutionary History, McGraw-Hill Publications, New York, 3-50. https://doi.org/10.2307/1445695

[42] Wilson, J.A., Mohabey, D.M., Peters, S.E. and Head, J.J. (2010) Predation upon Hatchling Dinosaurs by a New Snake from the Late Cretaceous of India. PLOS Biology, 8, e1000322. https://doi.org/10.1371/journal.pbio.1000322

[43] Perle, A., Norell, Chiappe, M.L. and Clark, J.M. (1993) Flightless Bird from the Cretaceous of Mongolia. Nature, 362, 623-626. https://doi.org/10.1038/362623a0

[44] Chiappe, L.M. (1995) Courier Forschungsinstitus, 181, 55-63.

[45] Walker, C.A. (1981) New Class of Birds from the Cretaceous of South America. Nature, 292, 51-53. https://doi.org/10.1038/292051a0

[46] Malkani, M.S. (2007) Trackways Evidence of Sauropod Dinosaurs Confronted by a Theropod Found from Middle Jurassic Samana Suk Limestone of Pakistan. Sindh University Research Journal (Science Series), 39, 1-14.

[47] Malkani, M.S. (2008) Marisaurus (Balochisauridae, Titanosauria) Remains from the 
Latest Cretaceous of Pakistan. Sindh University Research Journal (Science Series), 40, 55-78.

[48] Malkani, M.S. and Sun, G. (2016) Fossil Biotas from Pakistan with Focus on Dinosaur Distributions and Discussion on Paleobiogeographic Evolution of Indo-Pak Peninsula. Global Geology, 19, 230-240. 